\title{
The ties that bind? Marriage formation, consanguinity and war in Lebanon and Palestine
}

\author{
Yara Jarallah ${ }^{1,2,3,4}$ (D)
}

Accepted: 6 November 2021 / Published online: 3 February 2022

(c) The Author(s) 2022

\begin{abstract}
The paper explores the link between the civil war (1975-1990) in Lebanon and the first Intifada (1987-1993) in Palestine, and women's transition to marriage and consanguinity. It marries the literature on demographic behaviour and social ties, and contributes to nascent literature on demographic behaviour in times of war extended to consanguinity. It uses a mixed methods approach using two nationally representative data sets- one from each country, complemented with in-depth interviews $(n=55)$. Estimation methods are a discrete-time hazard model for entry into marriage and a discrete-time competing risks model for type of marriage. Findings provide empirical support for a war-induced effect on marriage formation, with a conflict-induced educational differential, especially for higher educated women in both settings. In times of war, Lebanese, and Palestinian women and their families resort to marriage as a protective strategy, especially when further educational pursuit is no longer deemed relevant because of both actual and perceived threats to women's safety. The strategies that women devise however, differ across both countries. Women in Lebanon strategize out-group marriages to diversify resources by establishing new alliances through marriage, while in-group marriages decline. Palestinian women on the other hand, show more heterogeneity, with some women maintaining existing familial bonds through in-group marriages, while others diversify resources through out-group marriages to facilitate new alliances. The differences in women's strategies in each setting is also indicative of other context contingent conflict-induced mechanisms. These operate through distorted sex-ratios against women in Lebanon, and through the breakage of kin networks through migration/displacement in Palestine.
\end{abstract}

Keywords Social capital · Marriage $\cdot$ Consanguinity $\cdot$ War $\cdot$ Lebanon $\cdot$ Palestine

Yara Jarallah

yara.jarallah@waikato.ac.nz

Extended author information available on the last page of the article 


\section{Introduction}

Macro level shocks and sudden ruptures associated with wars and conflicts are likely to affect marriage formation (Clifford et al., 2010; Shemyakina, 2013). Although studies on marriage formation as an outcome of war are emerging in the literature (Jayaraman et al., 2009; Valente, 2011), very few are those studies that empirically explore the link between war and consanguinity (Teerawichitchainan, 2012). Similarly, the literature on social capital and ties (Lin, 2005) has not been explored in the context of war in relation to consanguinity as a demographic outcome. Theoretically, conflict and war could facilitate a woman's entry into marriage (Valente, 2011). Women and their families could see marriage formation as a way of protection in times of war and its associated insecurities. Similarly, women and their families may seek to strengthen their existing ties and maintain family solidarity through marriage (Randall, 2005) by marrying a relative. Alternatively, they may seek to bridge relations with others outside the family to secure new alliances and diversify resources in times of war by marrying a non-relative. This paper aims to study the link between civil war (1975-1990) in Lebanon and the first Intifada (1987-1993) in Palestine, and women's transition to marriage and consanguinity. Specifically, it asks, does war facilitate or hinder women's entry into marriage in Lebanon and Palestine? What types of marriages are formed and what motivates those decisions?

The paper contributes to the nascent literature on demographic behaviour in times of war, extends it to consanguinity, and makes several substantive and methodological contributions. First, it innovates by combining two strands of literature, demographic behaviour, and social ties/capital, in times of war. Second, it leverages a mixed methods approach to the study of marriage formation and consanguinity by using two nationally representative datasets for Lebanon and Palestine and complements that with 55 in depth interviews in both countries. Altogether, findings provide empirical evidence of a war-induced effect on marriage formation with a conflict-induced educational differential, especially for higher educated women in both settings. In times of war, Lebanese and Palestinian women, and their families, resort to marriage as a protective strategy, especially when further educational pursuit is no longer deemed relevant because of both actual and perceived threats to women's safety. The strategies that women devise however, differ across both countries. Women in Lebanon, strategize outgroup marriages to diversify resources by establishing new alliances through marriage, while in-group marriages decline. Palestinian women on the other hand, show more heterogeneity, with some women maintaining existing familial bonds through in-group marriages, while others diversify resources through outgroup marriages to facilitate new alliances. The differences in women's strategies in each setting are also indicative of other context contingent conflict-induced mechanisms. These operate through distorted sex-ratios against women in Lebanon, and through the breakage of kin networks through forced migration/displacement in Palestine. 
The paper begins by situating marriage formation and consanguinity within the nascent literature on demographic behaviour in times of war, cites the nuances that the social ties/capital literature may offer in this regard and henceforth generates a set of hypotheses. The sections that follow describe the study settings, including marriage arrangements and kin relations, and methods. Results are then presented from both countries and the final section concludes.

\section{Background}

\section{Marriage formation, consanguinity, and war}

Studies on marriage formation as a demographic outcome in times of war and conflict in low and middle-income countries are slowly gaining momentum (Clifford et al., 2010; Jayaraman et al., 2009; Randall, 2005; Shemyakina, 2013; Teerawichitchainan, 2012; Valente, 2011). The limited evidence to date is mixed and suggests that whether marriages are formed or not vary depending on the nature of war and the characteristics of the population affected. For example, Jayaraman et al. (2009), Clifford et al. (2010), and Shemyakina (2013) show a negative effect of war resulting in marriage delay. Some of the underlying mechanisms linking conflict with (delayed) marriage formation in these three studies, signal the imbalance in the sex-ratios against females (from male casualties and male labour migration), economic hardships (reducing families' abilities to afford the costs associated with marriage) and disruptions in family and kinship ties (associated with loss of siblings and displacement from war).

On the other hand, Valente (2011) show a positive effect of war resulting in marriage formation. Here changes in schooling or educational attainment is one of the mechanisms through which conflict affects (early) marriage formation. Alternatively, marriage formation can remain resilient to war in which no effect is observed (Randall, 2005; Teerawichitchainan, 2012).

Consanguinity or marriage between biological relatives is a type of marriage formation that has been the subject of much recent research over a broad range of disciplines including the social sciences (Schellekens Kenan \& Hleihel, 2017; Harkness \& Khaled, 2014; Mobarak et al., 2013) the biosocial sciences (Abbasi-Shavazi et al., 2008; Shaw \& Raz, 2015) and the medical sciences (Al-Gazali \& Hamamy, 2014; Bittles \& Hamamy, 2010). This is because despite being rare in developed countries, ${ }^{1}$ consanguinity- though declining- is still prevalent in developing countries including the Middle East and North Africa, (Harkness \& Khaled, 2014; Tfaily, 2005). Nevertheless, studies on consanguinity as a demographic outcome in times of war and conflict is rarely studied if at all (see Teerawichitchainan, 2012 for an exception). ${ }^{2}$ Instead, most of the studies to date continue to be shaped by Goode's modernisation

\footnotetext{
${ }^{1}$ Today, with the exception of migrant communities and transnational marriages, consanguineous marriages are very rare in the developed countries and account for less than $1 \%$ of marriages (De Koning, Storms \& Bartels 2014; Romeo \& Bittles 2014).

${ }^{2}$ Although consanguinity is not a demographic outcome of the study, the article points to the role of kinship systems in facilitating marriage formation during war.
} 
Table 1 Median age at first marriage and consanguinity by marriage cohort and country

\begin{tabular}{lllll}
\hline Marriage Cohort & $\begin{array}{l}\text { Median age at } \\
\text { marriage }\end{array}$ & $\begin{array}{l}\text { Total consanguineous } \\
\text { marriage }(\%)\end{array}$ & $\begin{array}{l}\text { First cousin mar- } \\
\text { riage }(\%)\end{array}$ & Kin marriage (\%) \\
\hline $\begin{array}{l}\text { Lebanon } \\
1962-1973\end{array}$ & 16.5 & 33.4 & 18.1 & 15.4 \\
$1974-1979$ & 18.5 & 30.0 & 18.1 & 11.8 \\
$1980-1985$ & 18.5 & 26.7 & 15.1 & 11.6 \\
$1986-1991$ & 20.5 & 23.7 & 13.9 & 9.8 \\
$1992-1997$ & 21.5 & 23.6 & 14.2 & 9.5 \\
$1998-2004$ & 22.5 & 21.8 & 12.1 & 9.7 \\
Palestine & & & & 23.7 \\
$1962-1973$ & 15.5 & 54.7 & 31.0 & 22.2 \\
$1974-1979$ & 17.5 & 55.3 & 33.1 & 20.3 \\
$1980-1985$ & 18.0 & 52.6 & 32.3 & 18.1 \\
$1986-1991$ & 17.5 & 45.6 & 27.4 & 17.2 \\
$1992-1997$ & 18.0 & 46.0 & 28.8 & 16.5 \\
$1998-2006$ & 18.5 & 40.2 & 25.6 & \\
\hline
\end{tabular}

Sources: Author's Calculation from the Lebanese Survey on Household Health (Papfam) 2004; Palestinian Family Health Survey (Papfam) 2006

theory and family change (Goode, 1963; Mobarak et al., 2013). Engaging directly or indirectly with the modernisation thesis, scholars advanced several mechanisms to help explain the persistence of this practice. Those can be summarised as economical (see Mobarak et al., 2013), functional (see Weinreb, 2008), structural (see Barakat \& Basten, 2014; Murphy, 2011) and cultural (see Holy, 1989; Shultz \& Lavenda, 2000). Despite being a useful framework, the limitations of these mechanisms in light of increasing political instability is acknowledged by some scholars (Barakat \& Basten, 2014; Bittles, 2015; Weinreb, 2008). In fact, the whole framework is contested for its reductionist view through the adoption of a binary (traditional versus modern) perspective (Johnson, 2006, p. 63). Indeed, despite showing a decrease in several countries in the Middle East and North African region (Schellekens Kenan \& Hleihel, 2017; Tfaily, 2005), consanguinity remained resilient to modernisation (Jurdi \& Sazena, 2003; Assaf \& Khawaja, 2009) and even resurgent in some countries in the region (Harkness \& Khaled, 2014; Sandridge et al., 2010). For Lebanon and Palestine, the two countries under scrutiny, consanguinity remained relatively constant at about $24 \%$ of all marriages in Lebanon and $46 \%$ of all marriages in Palestine for a decade (between 1986 and 1997), before declining to 22 and $40 \%$ of all marriages respectively in the most recent period (see Table 1). The resilience of consanguinity, and the limited and mixed evidence on the impact of war on marriage formation broadly, calls for more empirical studies on the impact of war through a closer look at potential war-induced mechanisms. Henceforth, the following section reviews some of this literature to generate hypotheses on the impact of war on women's transition to marriage and consanguinity. 


\section{War-induced mechanisms and hypotheses}

Few studies explore the social shocks that war brings about to populations, particularly families, and the coping strategies they devise including marital behaviour (see Randall, 2005 for an exception). This is especially salient as Randall (2005) observes, "marriage is the demographic behavior over which people have most control [and can] be manipulated in an attempt to secure various ends, some of which may be conflict related" (p. 309).

\section{Family protection and security}

In times of conflict, marriage formation can be used as a strategy to secure alliances and strengthen bonds (Randall, 2005). One can argue therefore, that the need to secure and protect one's family is one of the war-induced social mechanisms that affect marriage formation. Although conflict-induced physical threats to safety (Shermayakina, 2013) and feelings of insecurities (Falkingham, 2000) are acknowledged in the literature on marriage formation, they are not interrogated on their own merit as potential war-induced mechanisms. Also, war does not only produce physical threats, but also social threats through the potential breakage of social networks. This becomes more salient, in contexts characterised by a state vacuum, where social safety nets are only available through social networks, especially through the family. In fact, scholars such as Suad Joseph (2004) argues that the civil war in Lebanon helps reinforce the central role of family as protector in the context of a weak Lebanese state. Indeed, her ethnographic work in Lebanon reveals the family as the only enduring institution of stability and security (p. 275). Such times help reinforce traditional practices such as endogamy (marriage from within the family to cousins or relatives) where family members turn to each other for economic help in times of financial stressors (Joseph, 2004). Similarly, studies from Palestine reveal the same thing, in the absence of a national state and in the continued protracted Israeli Occupation, families and kinship ties become vital for survival, not only through a sense of belonging, but most importantly as providers of protection, security and guidance (Assaf \& Chaban, 2013; Haj, 1992; Khawaja, 2000).

The effect of war is seldom directly inferred from survey data, this is because there is no explicit question about an individual's exposure to war (Brück et al., 2010). This can be resolved however, by studying life course transitions (such as marriage formation) through statistical modelling of event histories (Wu, 2003), where the effect of conflict and war can be modelled through a series of time-varying period indicators. Changes in marital behaviour during war and conflict periods can hence be interpreted as a war effect. Thus, my first hypothesis (H1) predicts that marriage formation would be more likely during periods of war and conflict to secure alliances and to strengthen bonds.

\section{Social capital}

The concept of social capital is particularly useful to interrogate in contexts of war. Indeed, when states are no longer able to provide basic safety nets to their citizens, 
social networks resume higher prominence in compensation for state vacuums particularly through the family. This is even more salient in contexts where marriage formation continues to play a central role in the lives of men, and especially women, and remains "the principle forum of recruitment to and reproduction of the social group" (Randall, 2005, p. 293). Social Capital according to Bourdieu (1983/1986) is "the aggregate of the actual or potential resources which are linked to possession of a durable network of more or less institutionalized relationships of mutual acquaintance or recognition" (p. 248). Indeed, the network-based premise of social capital is accredited by many scholars (Bourdieu, 1980; Coleman, 1988; Erickson, 1996; Lin, 2005; Putnam, 1995). In fact, Lin (2005) develops a network-based theory of social capital distinguishing between patterns of social relations that vary in intensity and reciprocity. He distinguishes between ties that bind and ties that bridge; typically, the ties that bind are intimate, share sentiment, provide mutual support, and are characterised by a dense network such as family and kin (Lin, 2005 p. 12). Alternatively, ties that bridge do not share a dense network and are in fact diverse in composition and resources (Lin, 2005). Whether ties bind or bridge, and their attribution to social capital lies in the purpose of action, this can be expressive- such as seeking solidarity, or instrumental- such as diversifying and gaining resources (Lin, 2005, p. 15). The expressive and instrumental purpose of action of ties that bind and bridge can be extended to marital behaviour in times of war.

If, as argued by Randall (2005), marriage formation is a strategy to strengthen existing bonds in times of conflict, then it may be conceived of as an expressive purpose of action to maintain solidarity among family members, and as such, marriage between relatives (that is consanguinity), can be the strategy to achieve this goal. As such, my second hypothesis (H2) postulates that transition to consanguineous marriage is more likely during the periods of war and conflict. Clearly, this would be contingent on having enough male cousins to choose from within the pool of available mates in the marriage market.

Alternatively, marriage formation may be devised as a strategy to secure new alliances in times of conflict (Randall, 2005). In which case, the purpose of action might be instrumental, as the goal is to bridge relations with others outside the family as a way to diversify resources. The potential breakage of kin networks from warinduced migration and displacement further strengthens this goal. Hence my third hypothesis (H3) predicts that transition to non-consanguineous marriage is more likely during periods of war and conflict.

\section{Perceived and actual threats to women's security}

Education pursuit can be affected in times of war and conflict by both perceived and actual threats to women's security (Johnson, 2010, p. 3). This makes the decision to postpone marriage for the pursuit of education no longer feasible. Hence, it might be a potential mechanism through which conflict and war could affect marriage formation (Valente, 2011). Indeed, a growing body of literature has shown how education attainment has been hampered in times of war and conflict (Islam et al., 2016), particularly for women, through both perceived and actual threats to security (Agadjanian \& Makarova, 2003; Cetorelli, 2014; Chamarbagwala \& Moran, 2011; Swee, 
2015; Shemyakina, 2011; Valente, 2011). ${ }^{3}$ Hence, my fourth hypothesis (H4) predicts that transition to marriage would be more likely for the highly educated women during the period of war and conflict compared to their lower educated counterparts.

As the literature does not really allow for predicting the direction of the association between marriage type, education, and conflict, I do not develop a distinct hypothesis of this relationship but do look at this empirically, and discuss some of the potential channels through which it might operate, including the context specific contingencies of this in the discussion section.

\section{Study settings}

\section{Lebanese and Palestinian contexts}

Lebanon and Palestine have always been portrayed at two ends of the spectrum with respect to their demographic makeup and in discourses around their fertility and nuptiality transitions (Rashad et al., 2005). Indeed, Lebanon is the forerunner of both the fertility and marriage transitions having the lowest fertility in the region at about 1.7 children per women in 2006 (PAPFAM, 2006), and an increasing percent of women never married by age 39 (about 24\%) by 2007 (United Nations World Marriage Data 2012,2013). Palestine on the other hand, has the highest fertility in the region (after Yemen) at around 4.2 children per women in 2010 (PCBS, 2013), and age at marriage has been going up but at a slower pace with only $11 \%$ of women still single by age 39 (United Nations World Marriage Data 2012, 2013). Despite the differences in the pace of change in fertility and marriage patterns, these two countries have similarities as well. Palestinian and Lebanese women both have the highest share of educated women in the region (Tabutin \& Schoumaker, 2005) with a literacy rate of $88.9 \%$ and $86.3 \%$ respectively (Giacaman et al., 2009), and have both suffered prolonged violence and conflict throughout their histories. These factors make both countries distinctively different than other countries of the region with respect to their socio-demographic profiles, but also comparatively different from each other in the pace of demographic change and the nature of the conflict that each country endured, therefore ideal for comparison in research examining war and conflict effects on marriage and consanguinity. Indeed, while religious sectarianism played an important role in starting the Lebanese civil war, resisting the Israeli Occupation has been the fuel of the first Intifada in Palestine. Despite their different nature, both conflicts were long, and examining their impact on marriage formation in both countries is warranted, especially considering the factors described above.

\footnotetext{
${ }^{3}$ While these studies have shown a reduced demand for education through restricted mobility and fear for women's safety, studies have also shown a reduction in the supply of education in times of conflict and war, through loss of infrastructure and destruction of educational facilities (see Justino, 2016 for a detailed review of demand and supply restrictions to education in times of conflict).
} 


\section{Protracted occupation and civil war}

The occupied Palestinian territories (oPt), is the name officially used by the United Nations to designate the lands that have a unique history dominated by conflicts, war and outside colonial and political domination (Khawaja, 2000). From centuries of colonisation by the Ottoman Empire, to the British mandate and up to the current protracted Israeli Occupation, the Palestinians underwent extraordinary demographic, economic and political conditions that characterise them as unique (Assaf \& Khawaja, 2009) and have no doubt been prominent in shaping their lives, behaviours and the overall social fabric of their society including marriage formation (Assaf \& Khawaja, 2009; Khawaja, 2000). Resisting the Israeli Occupation started with the first Palestinian popular uprising (Intifada) that broke in 1987 against Israeli military Occupation and lasted till 1993. The second Palestinian uprising (Intifada) broke in the year 2000 fuelled by widespread discontent with the failure of the Oslo Accords (that were signed by the Palestine Liberation Organization and Israel in 1993) to address accelerating Israeli confiscation of Palestinian lands and by the shortcomings of the Palestinian National Authority. Starting in 2000, the lives of the Palestinians under the Israeli Occupation have become much harder with the intensification and erection of over 600 Israeli checkpoints and the massive construction of the Separation Wall annexing $10 \%$ of the total land area of the West Bank. This dramatically segments Palestinian governorates in the West Bank from one another, restricting Palestinian access to health care and education, and separates families from their places of work and land (Giacaman et al., 2009).

Similarly, Lebanon has been affected by over 15 years of civil war. Between 1975 and 1990 the war affected the demographic and social make-up of the Lebanese population. Despite its small population of about 5.2 million people (World Population Data Sheet, 2015), ${ }^{4}$ Lebanon is home to 18 distinct religious sects (most of which belong to one of the two larger clusters of Muslims and Christians). This variety, however, has been a source of contention, and has no doubt been a contributing factor to the ensuing civil war. This is because in the absence of a strong Lebanese state, sects play an important role in Lebanese society and constitute the primary social organisation through which political security is maintained (Hudson, 1985). This is why both data and research that deal with population dynamics in Lebanon are sparse (Chamie, 1977). Indeed, the last official census in Lebanon was undertaken in 1932 during the French mandate, the findings of which comprised the statistical basis for the confessional political system that Lebanon operates under, ${ }^{5}$ distributing public positions among the major religious sects as the populations were then enumerated. To prevent political upset, most of the data that is collected or published on Lebanon afterwards does not make reference to religious affiliation and

\footnotetext{
4 This number also includes a fair number of Palestinian, Iraqi, and Syrian refugees.

5 After it gained independence in 1943.
} 
is only broken down by governorates or administrative units (Chamie, 1977; Faour, 2007). ${ }^{6}$

The occupied Palestinian Territories is divided into two separate areas, the West Bank and the Gaza Strip, and is home to around 4.5 million Palestinians (World Population Data Sheet, 2015). The Gaza Strip has five governorates and although there are severe restrictions on movement of goods and people between the Gaza Strip and the West Bank; there is no variation in the impact of the Israeli Occupation within the Gaza Strip, and it is also largely socially homogeneous. There is a lot of variation within the West Bank however, not only with respect to the impact of the Israeli Occupation with its increasing closures, but also within larger regions (of the North, Center and South) where the governorates are located, showing distinctive identities and social characteristics (Taraki \& Giacaman, 2006).

Further, the six governorates or administrative areas that make up Lebanon underwent major changes as a result of the civil war, including war-related deaths, declining fertility, and internal and international migration (Faour, 2007). Although there are no accurate statistics since the 1932 census, estimates show that the Christian Maronites, Shiites and the Sunnis are 22.5, 28.1 and 28.1\% respectively, with Christian Maronites being the smallest among them (Faour, 2007). With the six governorates (administrative districts), the Christian Maronites are predominantly in Mount Lebanon; the Shiites are predominantly in South Lebanon and Nabatieh, while the Sunnis are predominantly in North Lebanon (Faour, 2007).

\section{Family, marriage and kin relations}

Family structure in the Arab world including Palestine and Lebanon has historically been characterised as patriarchal and patrilocal with the extended family (or lineage) being the most important determinant of an individual's rights and responsibilities (McDonald, 1985, p. 89). Indeed, the dominant Arab family structure facilitates the strength of patriarchy as it is patrilineal, where the descent is based on the male line and antecedence is given to sons over daughters, and patrilocal with adult married sons living either with their parents or within close proximity to them, while daughters marry out (Barakat, 1985, 1993; Courbage \& Todd, 2014; Olmsted, 2005). It is because of this system that Arab families have traditionally been endogamous with preference given to cousins -either first cousins or kin (Courbage \& Todd, 2014). Nevertheless, such view of 'the' Arab family as singular and static has been contested by scholars, who argue that Arab families are diverse and are constantly invented and reinvented (Joseph \& Rieker, 2008 p. 13) especially as a response to crisis (Sayigh, 2005, 2008). Despite the paucity of research in this domain, evidence from Lebanon and Palestine reveal the vital role of families and kinship ties for security in times of war and protracted Occupation where Palestinian (Saygih, 1981) and Lebanese (Joseph, 2000) 'familialism' including marriage formation, is seen as an adaptive strategy of survival.

\footnotetext{
${ }^{6}$ This data limitation persists till this date and is in fact one of the reasons why Lebanon is perhaps one of the very few countries in the world (if not the only one) with no census data.
} 
Marriage is a central part of both the Lebanese and the Palestinian culture, it is considered both a family and an individual matter (authors). In fact, earlier ethnographic work reveals the importance of family in the decisions surrounding marriage formation as it is conceived not only as a marriage between two individuals, but also, a marriage between two families (authors). Nevertheless, marriage is no longer universal in both countries especially for women (Rashad \& Osman, 2003; Rashad et al., 2005). Indeed, the median age at marriage is increasing over time in both countries yet at a faster pace in Lebanon (see Table 1), and there are a growing number of women that are still single by age 39 in Palestine $(11.3 \%)$ and particularly Lebanon (23.7\%) by 2007 (United Nations World Marriage Data 2012, 2013). Although the percentage of women marrying young has historically been higher in Palestine than Lebanon, it is declining in both countries with less than 1 in 10 women married between 15 and 19 years in 2007 in Palestine (6.0\%) and Lebanon (3.3\%) (United Nations World Marriage Data 2012, 2013). This is because both Lebanese and Palestinian personal status laws recognise minimum age at marriage, which has historically been different across region (Palestine) and sectarian (Lebanon) lines. ${ }^{7}$ Sectarian differences are still present in Lebanon, but the minimum legal age at marriage is uniform in the West Bank and Gaza at 16 for girls and 17 for boys-with unsuccessful lobbying by political women's organisations to increase the minimum age to 18 for both boys and girls- (Welchman, 2000). In Lebanon, the minimum age of marriage for girls in the Ja'fari sect (Shiites) is puberty, while it is 17 and 18 for all other sects -Christians, Druze and Sunnis- (Shehadeh, 1998).

Very few studies address marriage arrangements and kin relations in Lebanon and Palestine (see Johnson, 2006; Johnson et al., 2009 for an exception). Most of the research in this domain either focuses on the legal sphere associated with the religious marriage contract, inheritance laws and the associated security provisions afforded to women through the dower ' mahr' (Joseph, 2000; Moors, 1995; Olmsted, $1999,2005)^{8}$, or continues to be shaped by earlier ethnographic studies that signal the uniqueness of Arab marriages dominated by paternal first cousin 'ibn 'amm' (Johnson et al., 2009). This, however, obscures the diversity of marriage arrangements (see for a review Johnson et al., 2009), and fails to address the context specific salience of the term. For example, in Lebanon and Palestine, one does not refer to cousin marriage by paternal or maternal first cousin but rather uses the term 'relative' 'qareeb' more broadly to signal consanguine marriages- including marriages to kin. Indeed, the notion of 'qaraba' or 'closeness' is argued by Johnson et al. (2009) as a more salient and flexible term to use when studying marriage arrangements and practices. Hence, in this paper I do not distinguish between first cousin and kin in

\footnotetext{
7 Both West Bank and Gaza were under different administration rules prior to the creation of the Palestinian Authority (PA) in 1994, with West Bank following the Jordanian personal status code, and Gaza following the Egyptian, before they were unified upon the establishment of the PA.

8 The dower 'mahr' sometimes also referred to as dowry, involves the transfer of cash, gold, and other forms of wealth from the husband to the wife upon marriage.
} 
the statistical and ethnographic analyses, but rather combine them both using the term consanguineous marriage to mean marriage to relatives 'qarayeb'.

\section{Data and methods}

This paper relies on a mixed methods approach as advocated by several authors in the social sciences for its ability to leverage on the strength of both methodologies (Laub \& Sampson, 1998; Small, 2011), and particularly in studies on conflict and violence (Thaler, 2015). Indeed, quantitative analyses are important in indicating patterns and unpacking mechanisms, while qualitative analyses can complement quantitative ones by contextualising statistical results and highlighting underlying decision-making processes and behaviours- hence the approach adopted in this paper.

\section{Data}

\section{Statistical data}

Two national datasets are used in the statistical analyses in this paper; The Palestinian Family Health Survey 2006 and the Lebanon Family Health Survey 2004. The former, is a nationally representative data set that is conducted by the Palestinian Central Bureau of Statistics (PCBS) in cooperation with the Pan Arab Project for Family Health (PAPFAM), UNICEF and UNFPA between November 12006 and 20 January 2007. It is the first Palestinian Family Health Survey, and constitutes part of a wide regional survey conducted in other Arab countries by the State of Arab League and includes the core Indicators of the Multiple Indicators Cluster Survey (MICS) supervised by UNICEF (PCBS, 2007). The survey is designed to collect, analyse and disseminate data on the Palestinian Population living in Palestine with a focus on family planning, maternal and child health, youth, the elderly, demography, and fertility. The sample design is a stratified two stage random sample from an updated sampling frame in 2003 that included all Palestinian Households. The first stage includes 325 enumeration areas (EAs) that are selected from all the Palestinian Territory. The second stage includes a systematic random sample of 40 households that are selected from each of the enumeration areas in the West Bank and Gaza Strip. Data is collected from 11,660 households and 10,648 ever married women 15-54 years with a response rate of $98.3 \%$ (PCBS, 2007). Data from the ever-married women and household questionnaires is used in this paper.

Similarly, the Lebanon Family Health Survey 2004 is part of the Arab Project for Family Health (PAPFAM) that is implemented by the League of Arab States in order to provide detailed and accurate data on family health, reproductive health,

\footnotetext{
${ }^{9}$ I do however, present results on consanguinity by marriage cohort and country, distinguishing first cousin from kin for descriptive purposes (see Table 1), and provide separate analyses for first cousin and kin as a robustness check.
} 
youth attitudes, elderly, in addition to the status and situation of Arab women. It is endorsed by the Ministry of Social Affairs and implemented in collaboration with the Central Administration of Statistics and the Arab Project for Family Health at the League of Arab States between April 52004 and November 27 2004. Data is collected from 6505 households and 3365 ever married women with a response rate of $96.2 \%$. The sample design is based on a two-stage sampling. The first stage is based on 449 geographic areas prepared by the Central Administration of Statistics and taken through systematic random sampling. The second sample is then taken from the geographic areas and consists of 7098 main dwellings that were selected from all over the country except for the Palestinian refugee camps (PAPFAM, 2006). Data from the ever-married women and household questionnaires is used.

\section{Ethnographic data and analyses}

The qualitative data used for this paper is only a subset of the author's larger project on marriage patterns that took place between July 2013 and January 2014 in Palestine and Lebanon and was approved by Brown University's Institutional Review Board under protocol (\#1307000896). This paper draws on the consanguinity subset collected through 55 in-depth interviews (each about 1-2 h long) with men and women in consanguineous unions from both countries. The interviews in the West Bank and Lebanon are collected by the author, while the interviews in Gaza are collected and transcribed by an experienced interviewer specifically trained for this study by the author. Participants are recruited through various channels, namely universities, non-governmental organisations and social networks with various communities and civil society organisations working across different regions and localities in both countries. Initial interviews started broad and open ended and then refined as more interviews were conducted. Some of the questions asked were about consanguineous practices between spouses (degree of relation to spouse), why consanguinity occurs, whether consanguinity is encouraged or forced, and the general circumstances leading to such unions including influential people that support or prevent such practices. This paper however, only draws on findings that contextualise statistical results, particularly with reference to war-induced mechanisms of family security and solidarity (expressive purpose of action of social capital). All 55 in-depth interviews following informed consent were audiotaped, transcribed verbatim, ${ }^{10}$ coded and analysed for salient themes by the author. The participants are distributed across gender (36 women and 19 men) age (20-55 years), education (preparatory, secondary and higher), setting (21 in West Bank, 16 in Gaza Strip and 18 in Lebanon), and geographic areas within each setting. The complete distribution of participants reflects the socio-economic, demographic, religious and regional diversity that characterise both countries as explained in the settings section above. To save space, the distribution of the participants are provided in the supplementary section (see Supplemental Table A1).

$\overline{10}$ With transcription assistance hired by the author for part of the interviews in the West Bank. 


\section{Statistical analyses}

Event-history models are applied to model the determinants of the hazard of marriage formation and of distinct paths of marriage formation types. The analysis uses the discrete-time hazard model with a logit function (cf. logistic regression) for entry into marriage and the discrete-time competing risks model for marriage type (cf. multinomial logistic regression) because of the competing risk of consanguinity and non-consanguinity (Allison, 1984). Hence, the discrete-time competing risks model simultaneously considers the odds of entering a consanguineous marriage and a non-consanguineous marriage versus remaining single. This approach allows for identifying factors whose effects work in similar or opposite directions in the transition to consanguineous and non-consanguineous unions. Women are considered to enter the risk of forming marriage at 10 and 12 for Lebanon and Palestine respectively and observations are included up to the year when they entered their first marriage or up to the year of the interview, ${ }^{11}$ if no transition is made.

The discrete-time logit models are based on person-years of exposure to the risk of marriage. This model takes the following functional form:

$$
\log \left(\frac{P_{i t}}{1-P_{i t}}\right)=\alpha_{t j}+\sum_{j=0}^{M} \beta_{m} X_{m i}
$$

where $P_{i t}$ is the probability of experiencing marriage for a single woman $i$ at year $t$ since her 10th or 12th birthday (for Lebanon and Palestine respectively). The model includes $m$ time-variant and time-invariant predictors described below.

The discrete-time multinomial logit models are based on person-years of exposure to the competing risk of consanguineous or non-consanguineous unions. The model takes the following functional form:

$$
\log \left(\frac{P_{i j t}}{1-P_{i j t}}\right)=\alpha_{t j}+\sum_{j=1}^{M} \beta_{m j} X_{m j i} \quad j=1, \ldots k
$$

where $P_{i j t}$ is the conditional probability of experiencing either consanguineous or non-consanguineous marriage ( $j=1$ for consanguinity, $j=2$ for non-consanguinity, $j=0$ for no event occurring or in other words remaining single) for a single woman $i$ at year $t$ since her 10th or 12th birthday (for Lebanon and Palestine respectively). Hence, the discrete-time multinomial logit model consists of $k$ equations, each contrasting the risk of one type of event (in this case consanguinity or non-consanguinity) with the risk that no event occurs (remaining single). The model includes $m$ time-variant and time-invariant predictors described below.

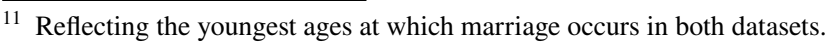




\section{Measurement of variables}

There are two main outcome variables in this paper; marriage formation which is dichotomous differentiating between marriage and no marriage, and marriage type differentiating between consanguineous marriage, non-consanguineous marriage and no marriage. Consanguineous marriage includes first paternal, first maternal, double first cousin and kin marriages (from the same clan). Marriage type hence has three response categories and is equal to 1 in the year that a woman reports marrying a cousin, 2 if married to a non-cousin and 0 if no marriage occurs and the woman remains single. The main explanatory variable is a time varying period indicator to distinguish the effect of civil war in Lebanon and the first Intifada in Palestine, measured in five-year periods. The earliest period corresponds to the early 1960 s, the latter part of the 1960s as the reference, and the more recent period corresponds to the 2000s. Other explanatory variables include birth cohort, measured in five-year cohorts, with the oldest cohort born on or before 1955, the middle cohort (reference) born during the latter half of the 1960s, and the youngest cohort born in the latter half of the 1980s and early 1990s. Because each region is unique as highlighted in the study settings section above, region distinguishes between Beirut (reference), Bekaa, North, South, Mount Lebanon and Nabatieh in Lebanon; and North (reference), Center and South of West Bank, and Gaza Strip in Palestine.

Education distinguishes between preparatory and less (reference), and secondary and more. In Palestine, locality is included to distinguish between women living in urban areas (reference), rural areas, and refugee camps. Finally, marriage is a time-dependent event, and the probability of marriage increases at younger ages then declines at older ages. To control for this change of probability and to capture the baseline hazard of marriage, a quadratic polynomial is used. To save space, the distribution of the independent variables in the analyses are provided in the supplementary section (see Supplemental Table A2).

\section{Results}

Table 1 presents results on median age at first marriage and consanguinity by country over time. The median age at first marriage is on the rise in both countries, yet for the entire period under observation (1962-2006), Lebanese women married at older ages than Palestinian women. The median age at marriage for women marrying in 1962-1973, rose from 16.5 to 22.5 in the most recent period for Lebanese women, and from 15.5 to 18.5 for their Palestinian counterparts. ${ }^{12}$ With respect to type of marriage, consanguinity is decreasing over time in both countries but is still prevalent at a non-negligible rate for the most recent period (see Table 1). Among Lebanese women, consanguinity decreased by 11.6 percentage points for the cohorts of women marrying in 1962-1973 and their counterparts marrying in 1998-2004. The same is observed for Palestine, but at a much sharper decline at

12 Median age at marriage was calculated by marriage cohort. 
Table 2 Odds ratios from discrete-time logit models of transition to marriage, Lebanon (2004)

\begin{tabular}{|c|c|c|c|}
\hline \multirow[t]{2}{*}{ Variable } & \multicolumn{3}{|l|}{ Marriage } \\
\hline & Model I & Model II & Model III \\
\hline Age & $1.681 * * *$ & $1.618 * * *$ & $1.618 * * *$ \\
\hline $\mathrm{Age}^{2}$ & $0.984 * * *$ & $0.984 * * *$ & $0.982 * * *$ \\
\hline \multicolumn{4}{|l|}{ Education } \\
\hline Preparatory and less (ref.) & 1.000 & 1.000 & 1.000 \\
\hline Secondary and more & $0.551 * * *$ & $0.545^{* * *}$ & $0.113 * * *$ \\
\hline \multicolumn{4}{|l|}{ Period } \\
\hline $1960-1964$ & $0.364 * *$ & $0.329 * *$ & $0.307 * *$ \\
\hline 1965-1969 (ref.) & 1.000 & 1.000 & 1.000 \\
\hline 1970-1974 & 1.029 & 1.123 & 1.219 \\
\hline 1975-1979 & 1.011 & 1.206 & $1.395 * *$ \\
\hline 1980-1984 & 0.874 & 1.156 & $1.380 *$ \\
\hline 1985-1989 & $0.768 * *$ & 1.152 & 1.392 \\
\hline 1990-1994 & $0.486 * * *$ & 0.871 & 1.051 \\
\hline 1995-1999 & $0.440 * * *$ & 1.028 & 1.211 \\
\hline $2000-2004$ & $0.278 * * *$ & 0.960 & 1.066 \\
\hline \multicolumn{4}{|l|}{ Region } \\
\hline Beirut (ref.) & 1.000 & 1.000 & 1.000 \\
\hline Bekaa & 1.082 & 1.057 & 1.071 \\
\hline North & $1.364 * * *$ & $1.347 * * *$ & $1.333 * * *$ \\
\hline Mount Lebanon & 1.115 & 1.096 & 1.086 \\
\hline South & 1.087 & 1.055 & 1.068 \\
\hline Nabatieh & 0.963 & 0.937 & 0.961 \\
\hline \multicolumn{4}{|l|}{ Birth Cohort } \\
\hline $1950-1954$ & & 1.128 & 1.263 \\
\hline 1955-1959 & & 1.187 & $1.224 *$ \\
\hline 1960-1964 & & 1.048 & 1.068 \\
\hline 1965-1969 (ref.) & & 1.000 & 1.000 \\
\hline 1970-1974 & & $0.802 * * *$ & $0.814 * * *$ \\
\hline 1975-1979 & & $0.594 * * *$ & $0.626^{* * *}$ \\
\hline 1980-1984 & & $0.377 * * *$ & $0.434 * * *$ \\
\hline $1985-1989^{a}$ & & $0.112 * * *$ & $0.115^{* * *}$ \\
\hline \multicolumn{4}{|l|}{ Education *Age } \\
\hline Preparatory and less*Age (ref.) & & & 1.000 \\
\hline Secondary and more*Age & & & $1.124 * * *$ \\
\hline \multicolumn{4}{|l|}{ Education $*$ Age $^{2}$} \\
\hline Preparatory and less $* \mathrm{Age}^{2}$ (ref.) & & & 1.000 \\
\hline Secondary and more*Age ${ }^{2}$ & & & 1.000 \\
\hline Number of person years & 97,302 & 97,302 & 97,302 \\
\hline Number of transitions & 3,359 & 3,359 & 3,359 \\
\hline Log pseudo likelihood & $-12,990$ & $-12,932.768$ & $-12,802.195$ \\
\hline Pseudo $\mathrm{R}^{2}$ & 0.1107 & 0.1146 & 0.1236 \\
\hline
\end{tabular}


Table 2 (continued)

\begin{tabular}{|c|c|c|c|}
\hline \multirow[t]{2}{*}{ Variable } & \multicolumn{3}{|l|}{ Marriage } \\
\hline & Model I & Model II & Model III \\
\hline Goodness of fit LR $\times 2(\mathrm{df})$ & $3233.57(16)$ & $3349.12(23)$ & $3610.27(25)$ \\
\hline \multicolumn{4}{|c|}{ Ref. $=$ reference category. $* * * p<0.01, * * p<0.05, * p<0.1$} \\
\hline
\end{tabular}

about 14.5 percentage points. The decrease in the most recent period, however, is preceded by a period where the total consanguinity rate remains relatively constant at about $24 \%$ of all marriages in Lebanon and $46 \%$ of all marriages in Palestine from 1986 to 1997 . Breaking down consanguinity into first cousin and kin, reveals that this relative stability is driven by a slight increase in first cousin marriage during this period, accompanied by a relative constant (Lebanon at about 10\%) and modest decline (Palestine at about 0.9 percentage points) in kin marriages. This might be the first sign of a potential war-effect that stalled consanguinity decline in both countries, as it also coincides with the latter period of the civil war in Lebanon and the first Intifada in Palestine. ${ }^{13}$

Tables 2 and 3 present three discrete-time logit models of the transition to marriage in Lebanon and Palestine respectively. The first model includes time-varying period indicators with selected covariates to assess whether periods of conflict significantly affect marriage propensity. These include education, given literature on the inverse relationship between education level and the likelihood of entering marriage from Lebanon (Saxena et al., 2004) and Palestine (Khawaja \& Randall, 2006), and region, in light of the distinct variation in the effect of civil war in Lebanon and conflict in Palestine on the different regions in each country as explained in more detail in the study settings section above. There is no evidence the periods of conflict significantly affect marriage propensity in Lebanon but clear evidence of this in Palestine noted by the significant first Intifada period indicator (1986-1990). The second model adds birth cohort variables to disentangle period from cohort specific conflict-induced marriage behaviours. To do so, we need to compare the period coefficients across the two models.

Figures 1 and 2 present period trends in marriage in terms of odds ratios from the first two models in both countries. The solid line represents the period model (Model I) and shows that marriage in terms of odds ratios declines almost continuously in Lebanon since the onset of the civil war in 1975 (Fig. 1) with no visible upward or

\footnotetext{
13 Total consanguinity resumed its decline for the most recent marriage cohorts in Lebanon (1998-2004) and Palestine (1998-2006) again driven by a decline in first cousin marriage. Kin marriages however, remained relatively stable during this period at about 10 percent in Lebanon and 17 percent in Palestine.
} 
Table 3 Odds ratios from discrete-time logit models of transition to marriage, Palestine (2006)

\begin{tabular}{|c|c|c|c|}
\hline \multirow[t]{2}{*}{ Variable } & \multicolumn{3}{|l|}{ Marriage } \\
\hline & Model I & Model II & Model III \\
\hline Age & $1.804 * * *$ & $1.753 * * *$ & $1.673 * * *$ \\
\hline $\mathrm{Age}^{2}$ & $0.975^{* * *}$ & $0.976^{* * *}$ & $0.976 * * *$ \\
\hline \multicolumn{4}{|l|}{ Education } \\
\hline Preparatory and less (ref) & 1.000 & 1.000 & 1.000 \\
\hline Secondary and more & $0.501 * * *$ & $0.490 * * *$ & $0.068 * * *$ \\
\hline \multicolumn{4}{|l|}{ Period } \\
\hline 1961-1965 & $0.292 * *$ & $0.280 * *$ & $0.255^{* *}$ \\
\hline 1966-1970 (ref) & 1.000 & 1.000 & 1.000 \\
\hline 1971-1975 & $1.175^{*}$ & $1.180^{*}$ & $1.294 * * *$ \\
\hline 1976-1980 & 0.906 & 0.910 & 1.071 \\
\hline 1981-1985 & $0.855^{* *}$ & 0.873 & 1.098 \\
\hline 1986-1990 & $1.226 * * *$ & 1.242 & $1.599 * * *$ \\
\hline 1991-1995 & 1.021 & 1.026 & $1.344^{*}$ \\
\hline 1996-2000 & 0.995 & 1.051 & $1.363^{*}$ \\
\hline 2001-2006 & $0.461 * * *$ & $0.662 * *$ & 0.764 \\
\hline \multicolumn{4}{|l|}{ Region } \\
\hline \multicolumn{4}{|l|}{ North West bank (ref) } \\
\hline Central West bank & $1.211 * * *$ & $1.205 * * *$ & $1.185^{* * * *}$ \\
\hline South West bank & $1.232 * * *$ & $1.214 * * *$ & $1.202 * * *$ \\
\hline Gaza Strip & $1.453 * * *$ & $1.453 * * *$ & $1.434 * * *$ \\
\hline \multicolumn{4}{|l|}{ Locality } \\
\hline Urban (ref) & 1.000 & 1.000 & 1.000 \\
\hline Rural & $0.895 * * *$ & $0.893 * * *$ & $0.909 * * *$ \\
\hline Refugee camp & $0.901 * * *$ & $0.903 * * *$ & $0.911 * * *$ \\
\hline \multicolumn{4}{|l|}{ Birth Cohort } \\
\hline 1951-1955 & & 0.953 & 1.129 \\
\hline 1956-1960 & & 1.049 & $1.167 * *$ \\
\hline 1961-1965 & & 1.025 & 1.071 \\
\hline 1966-1970 (ref) & & 1.000 & 1.000 \\
\hline 1971-1975 & & 1.058 & 1.038 \\
\hline 1976-1980 & & 1.051 & 1.048 \\
\hline 1981-1985 & & 0.963 & 1.044 \\
\hline $1986-1992^{\mathrm{a}}$ & & $0.456 * * *$ & $0.496 * * *$ \\
\hline \multicolumn{4}{|l|}{ Education*Age } \\
\hline Preparatory and Less*Age (ref) & & & 1.000 \\
\hline Secondary and More*Age & & & $1.337 * * *$ \\
\hline \multicolumn{4}{|l|}{ Education $*$ Age $^{2}$} \\
\hline Preparatory and less*Age ${ }^{2}$ (ref) & & & 1.000 \\
\hline Secondary and more*Age ${ }^{2}$ & & & $0.994 * * *$ \\
\hline Number of Person Years & 157,599 & 157,599 & 157,599 \\
\hline Number of Transitions & 10,643 & 10,643 & 10,643 \\
\hline
\end{tabular}


Table 3 (continued)

\begin{tabular}{llll}
\hline Variable & Marriage & \\
\cline { 2 - 4 } & Model I & Model II & Model III \\
\hline Log pseudo likelihood & $-34,761.43$ & $-34,644.711$ & $-34,218.786$ \\
Pseudo R & 0.1078 & 0.1108 & 0.1217 \\
Goodness of fit LR $\times 2$ (df) & $8396.64(16)$ & $8630.08(23)$ & $9481.93(25)$ \\
\hline
\end{tabular}

Ref. $=$ reference category. $* * * p<0.01, * * p<0.05, * p<0.1$

${ }^{a}$ Estimates for the youngest cohort needs to be treated with caution as it is a reflection of this cohort's person year contribution which is only based on observations till year 20 after which they are censored. As a significant proportion of marriages continue to occur after that age, I have likely underestimated the odds of marriage for this birth cohort and the current estimates are by no means a reflection of their overall life time odds of getting married

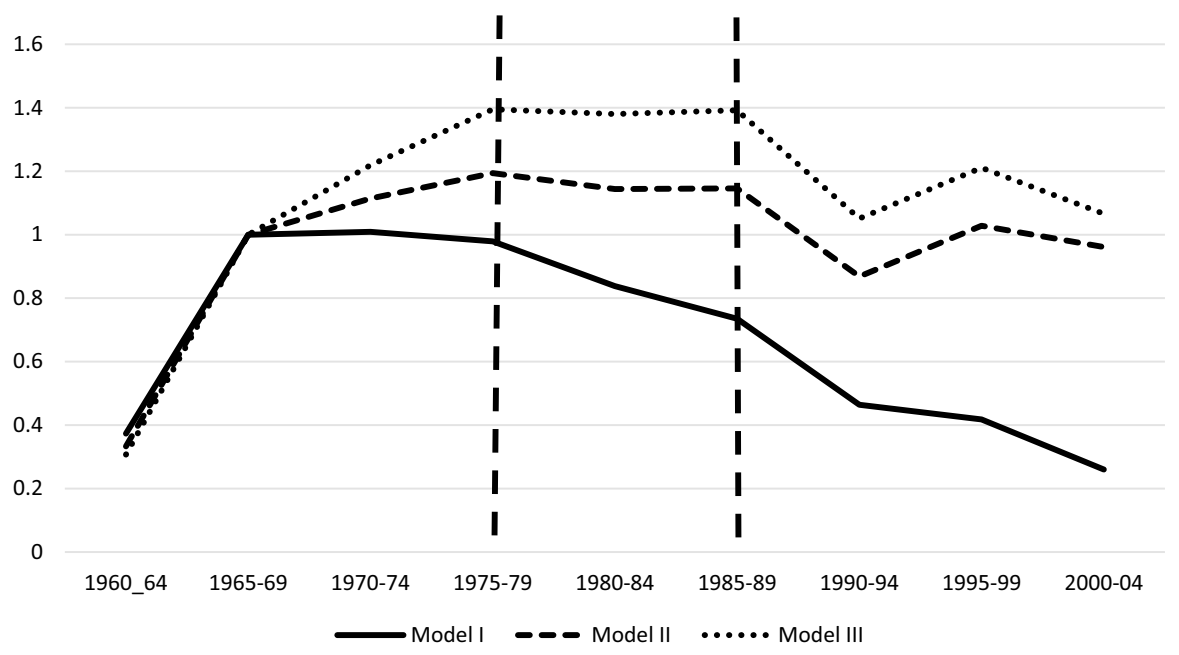

Fig. 1 Period Trends in Marriage in terms of odds ratios, Lebanon 1960-2004. Note Figure reports results from Table 2; Period effect controlling for age, age ${ }^{2}$, education and region (Model I), additionally controlling for cohort (Model II), and further controlling for education-baseline interactions and education-quadratic-baseline interactions (Model III), dashed vertical lines refer to the Period of Civil War

downward trend in Palestine apart from a steep increase in marriage during the onset of the first Intifada in 1986 (Fig. 2). When birth cohort variables are added to the model (Model II), marriage in terms of odds ratios (dashed line) increases slightly but then remains relatively stable throughout the period of the civil war (1975-1990) before it declines again in Lebanon (Fig. 1), while the pattern remains essentially the same in Palestine even after adding birth cohort variables (Fig. 2). This suggests that had it not been for cohort influences, marriage would have declined in Lebanon during the civil war (1975-1989) while in Palestine, cohort influences do not seem to affect the observed period trends in marriage. 


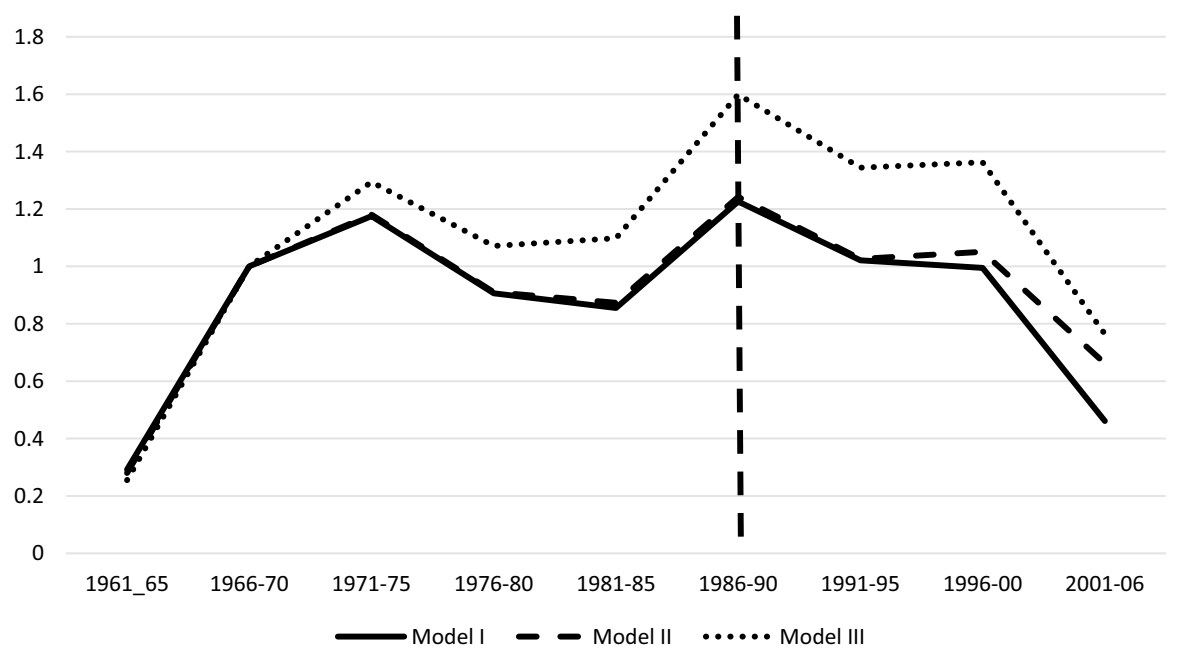

Fig. 2 Period Trends in Marriage in terms of odds ratios, Palestine 1961-2006. Note Figure reports results from Table 3; Period effect controlling for age, age ${ }^{2}$, education, region and locality (Model I), additionally controlling for cohort (Model II), and further controlling for education-baseline interactions and education-quadratic-baseline interactions (Model III), dashed vertical line refers to the Period of First Intifada

Because age patterns of marriage might differ by education level, Model III presents results of an adjusted model that accounts for an interaction between baseline hazard and education (likelihood ratio tests show that the interactions are significant in both countries, $p$ value $=0.000$ ). The dotted line presents these results and reveals an even more visible war effect compared to the dashed line, with a stagnant marriage trend in terms of odds ratios for Lebanon throughout the civil war period (Fig. 1) and a visible spike in marriage during the first Intifada in Palestine (Fig. 2). Consistent with the marriage trends observed in Figs. 1 and 2, inspecting the results of Model III in Tables 2 and 3 shows that there were both conflict-induced period and cohort influences on marriage propensity in Lebanon (Table 2). This is evident by the very significant conflict period indicators for most of the civil war period (1975-1984). To determine which cohorts contributed to the stagnant marriage trend, I now inspect the coefficients of the birth cohort variables. Women born in 1955-1959 had the highest significant odds of marriage. Those women would have reached marriageable ages during the civil war, thereafter, referred to as the war-cohort, as they would have been between 16 and 20 years old at the civil war onset in 1975 at which the median age at marriage for women during that period is 18.5 years (see Table 1). The conflict period influences on marriage propensity in Palestine (Table 3) is evident by the very significant period indicator for the first Intifada (1986-1990). This period is also the strongest in magnitude in comparison to other time periods.

Consistent with evidence suggesting an educational gradient in marriage in other world regions (Kalmijn, 2013), I test whether the impact of war and conflict on marriage varies significantly with level of education in both of my settings 

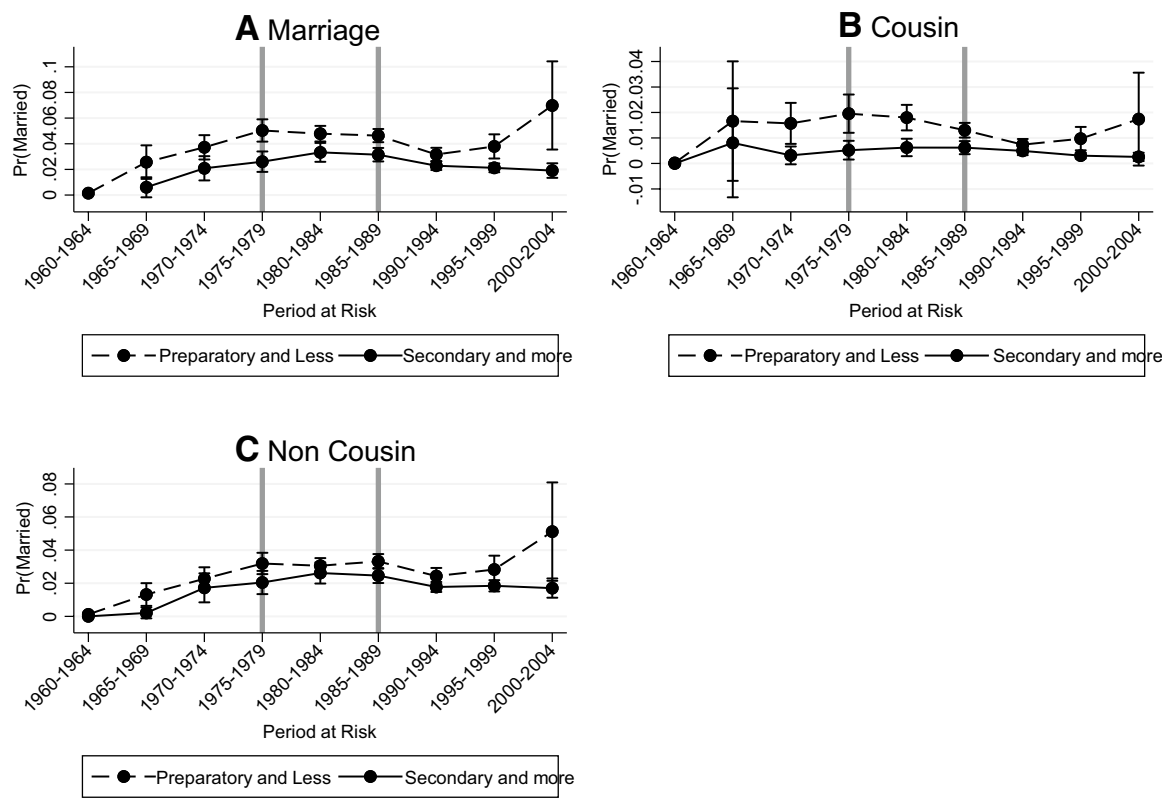

Fig. 3 Interaction between Period and Education, Lebanon 1960-2004. Notes Results are based on discrete-time hazard model (Panel A) and discrete-time competing risks models (Panels B and C) presented in Tables 2 (Model III) and 4 (Model I). Models control for age, age ${ }^{2}$, education, region, birth cohort, education-baseline interactions and education-quadratic-baseline interactions. In addition, results control for period-baseline interactions. Vertical bars denote $95 \%$ confidence intervals. Two thick grey lines denote the civil war period

(likelihood ratio tests show that the interactions are significant in both settings, $p$ value $=0.0003$ ). To do so, I present results from an interaction between time varying period indicators and education (Figs. 3 and 4). While there is no clear distinct variation within each education level across the different time periods in Lebanon, especially for women with secondary plus education, results reveal that marriage propensity increased for both groups at the onset of the civil war, and remained relatively stable throughout with a slight increase for the higher educated women in the period following the civil war onset (Fig. 3: Panel A). Results are more visible for Palestine, with a clear increase in marriage propensity for both education groups during the first intifada, especially for the more educated (Fig. 4: Panel A). While overall marriage propensity is higher for women with lower education in both countries, what is evident is that the war period has slightly narrowed the gap between both groups of women, making marriage propensity especially higher for the more educated during those periods, particularly in Palestine. This supports my hypothesis on education (H4) which stipulates that transition to marriage during conflict and war is more likely for the highly educated women compared to their lower educated counterparts. Qualitative results provide further evidence of this, as women and their families resort to marriage as a protective mechanism considering lack of security (H1), and lack of educational opportunities as a result of difficult mobility from actual and perceived 

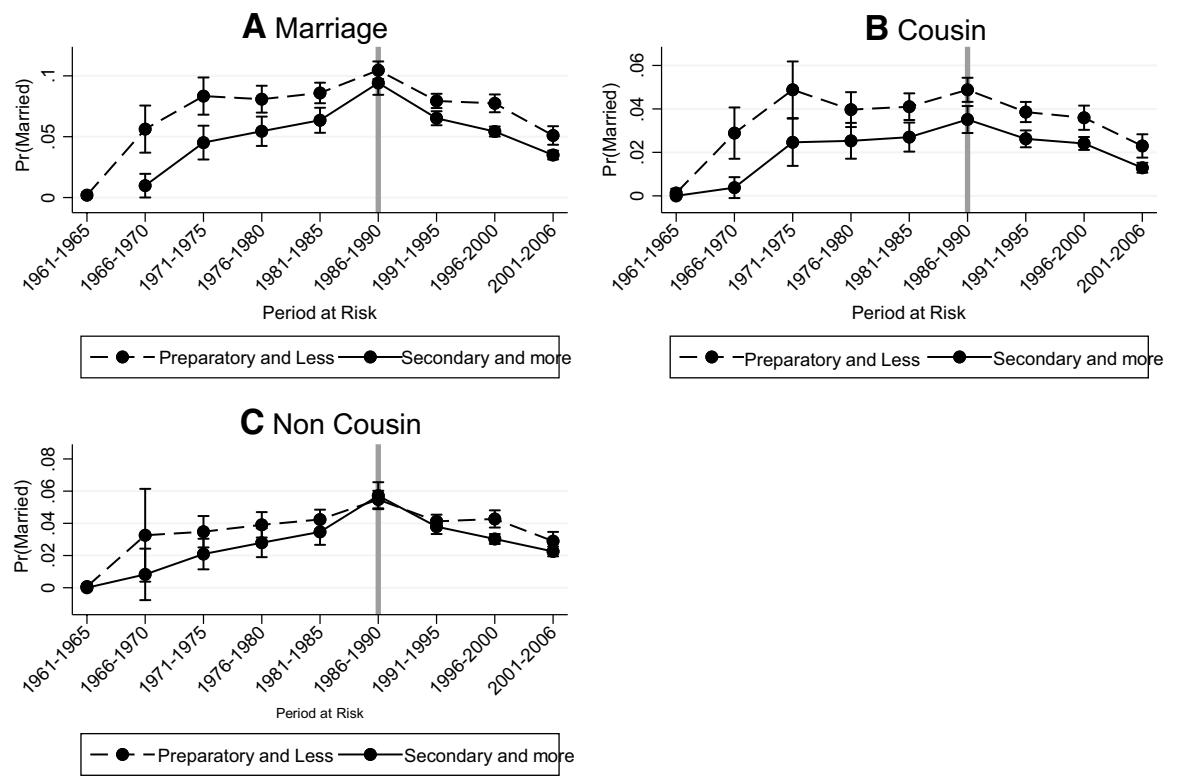

Fig. 4 Interaction between Period and Education, Palestine 1961-2006. Notes Results are based on discrete-time hazard model (Panel A) and discrete-time competing risks models (Panels B and C) presented in Tables 3 (Model III) and 5 (Model I). Models control for age, age ${ }^{2}$, education, region, locality, birth cohort, education-baseline interactions and education-quadratic-baseline interactions. In addition, results control for period-baseline interactions. Vertical bars denote $95 \%$ confidence intervals. Thick grey line denotes the first intifada period

threats to women's safety (H4) associated with the first Intifada (Palestine) and the civil war mobility restrictions (Lebanon). The quote below is from a woman in Palestine, the paralysis of the educational system and the accompanying insecurity facilitated her marriage.

"The first Intifada broke as soon as I finished my secondary school education, universities closed and we started smuggling our way into uninhabited houses in Jerusalem to study but we suffered a lot and my education was delayed." Woman 45 years with a Diploma Degree from Palestine.

Similarly, parents of the Lebanese woman below see marriage as a protective mechanism considering lack of security and lack of educational opportunities as a result of civil war mobility restrictions and perceived threats to women's safety.

"There was civil war and roads were very dangerous, so parents were right to be scared to send their daughters to study." Woman 49 years with secondary education from Lebanon.

This provided evidence in support of my first and fourth hypotheses for both Palestine and Lebanon. 


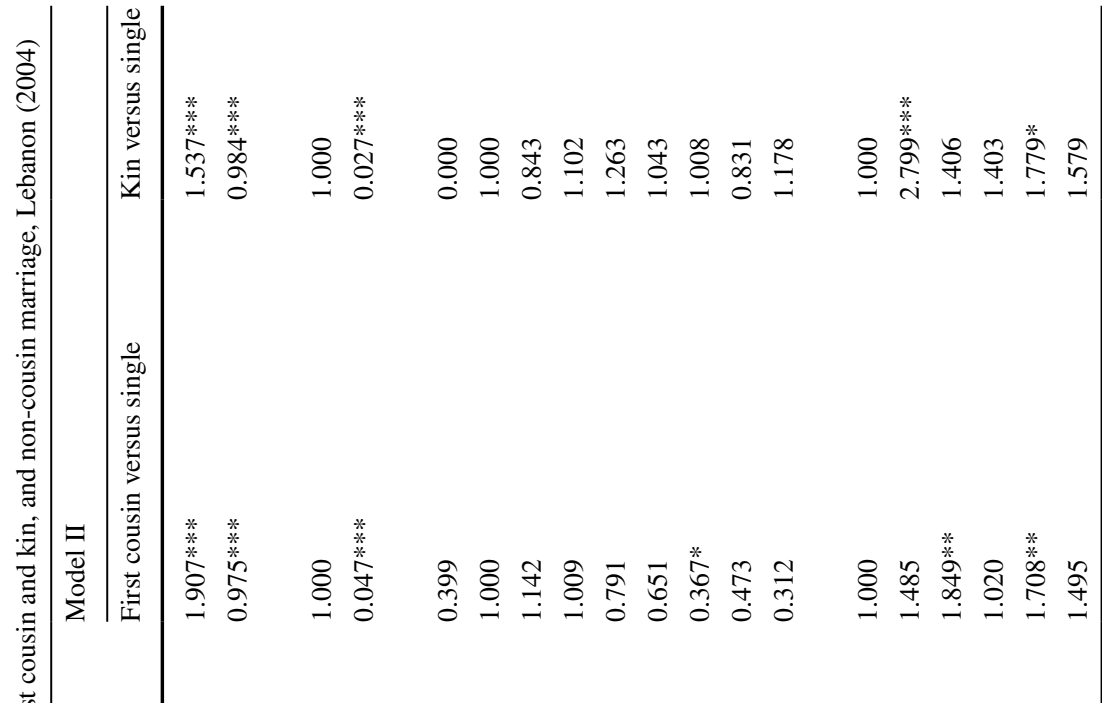

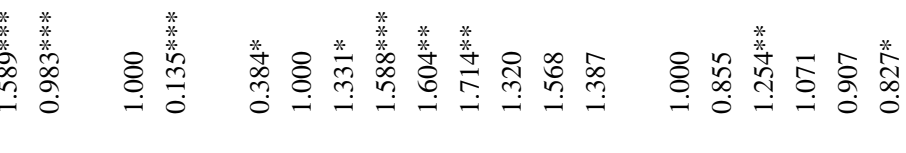

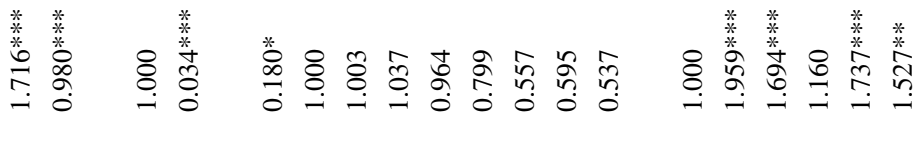

隶

嵌

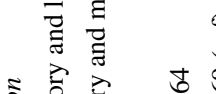

巴્仓

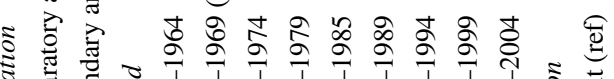

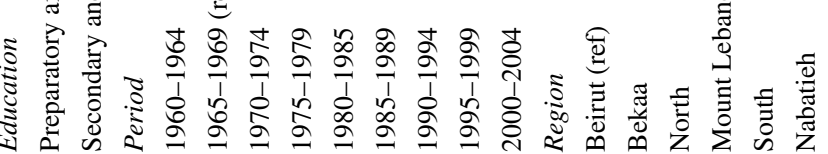

竞

电要 


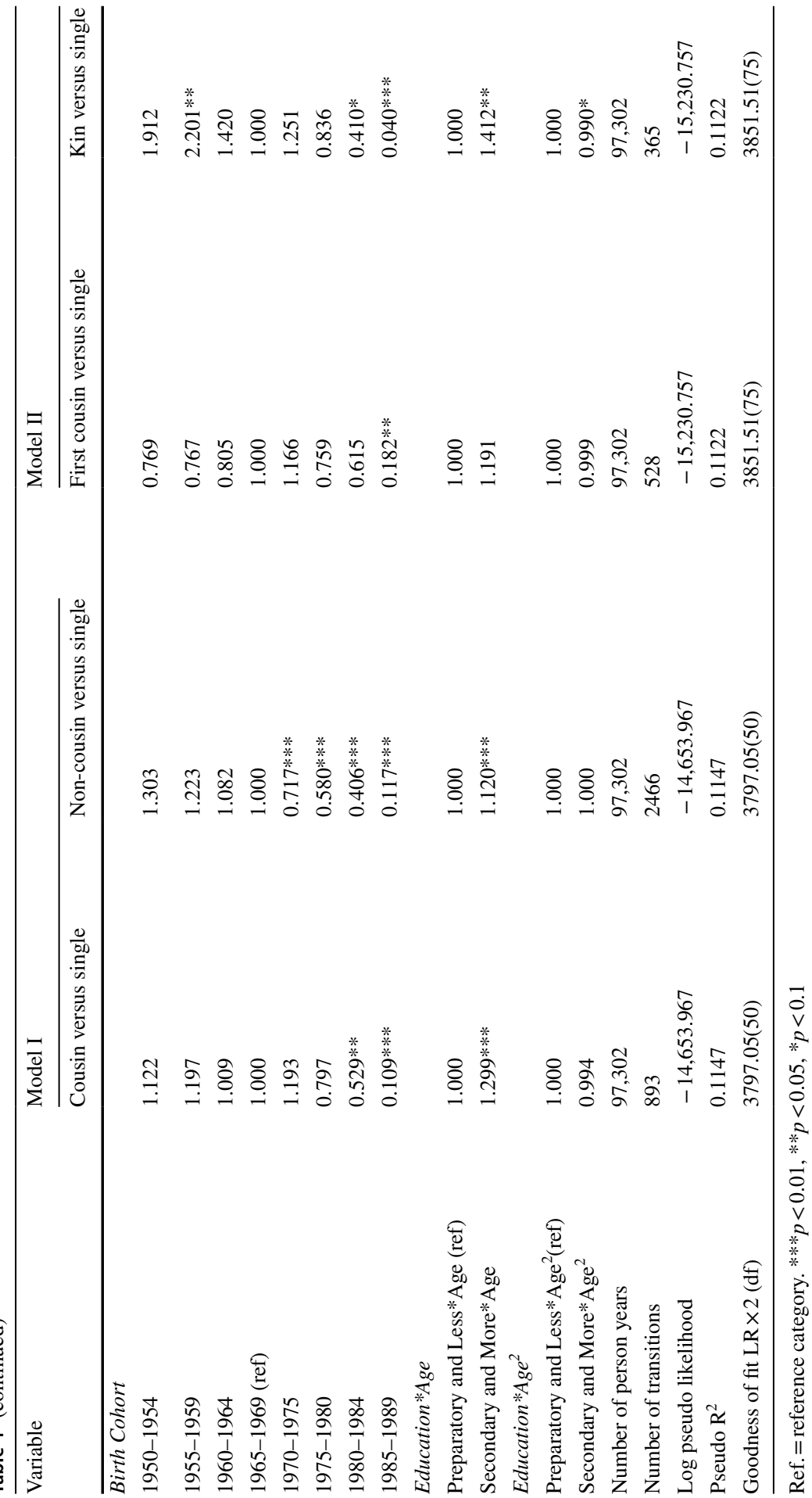




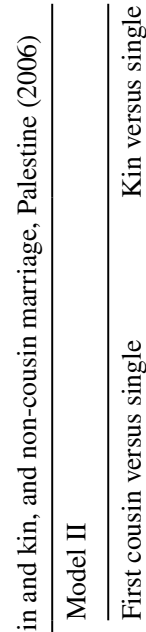

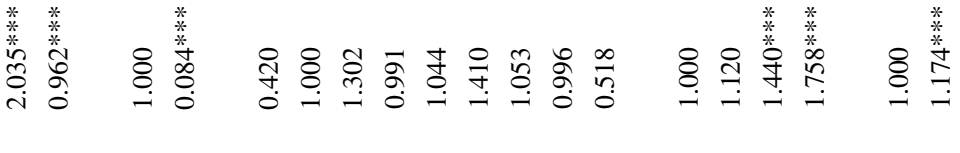

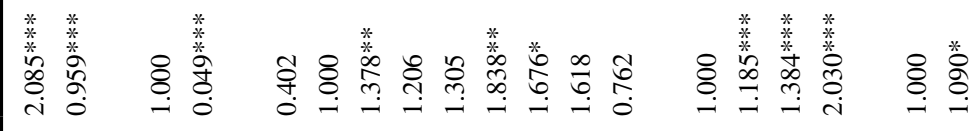

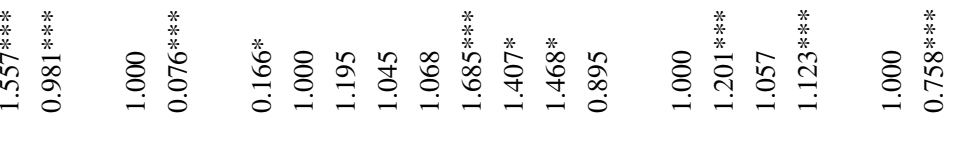

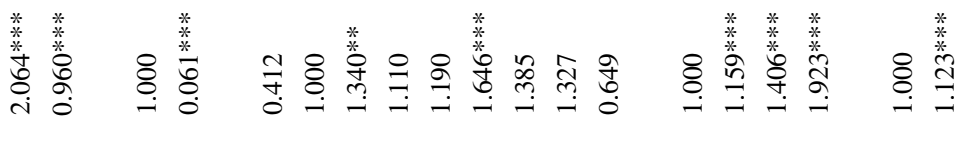

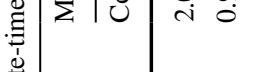

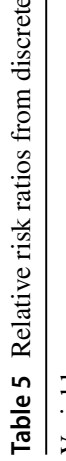

$\overparen{\overparen{Q}}$

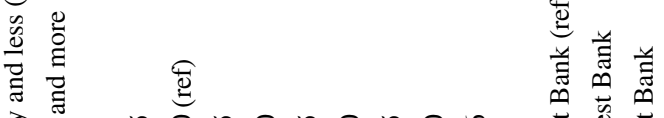

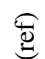

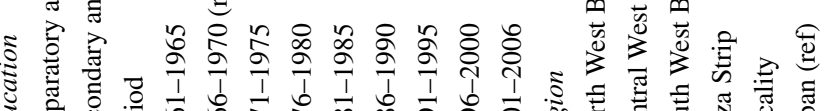

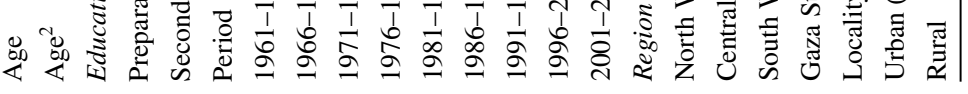




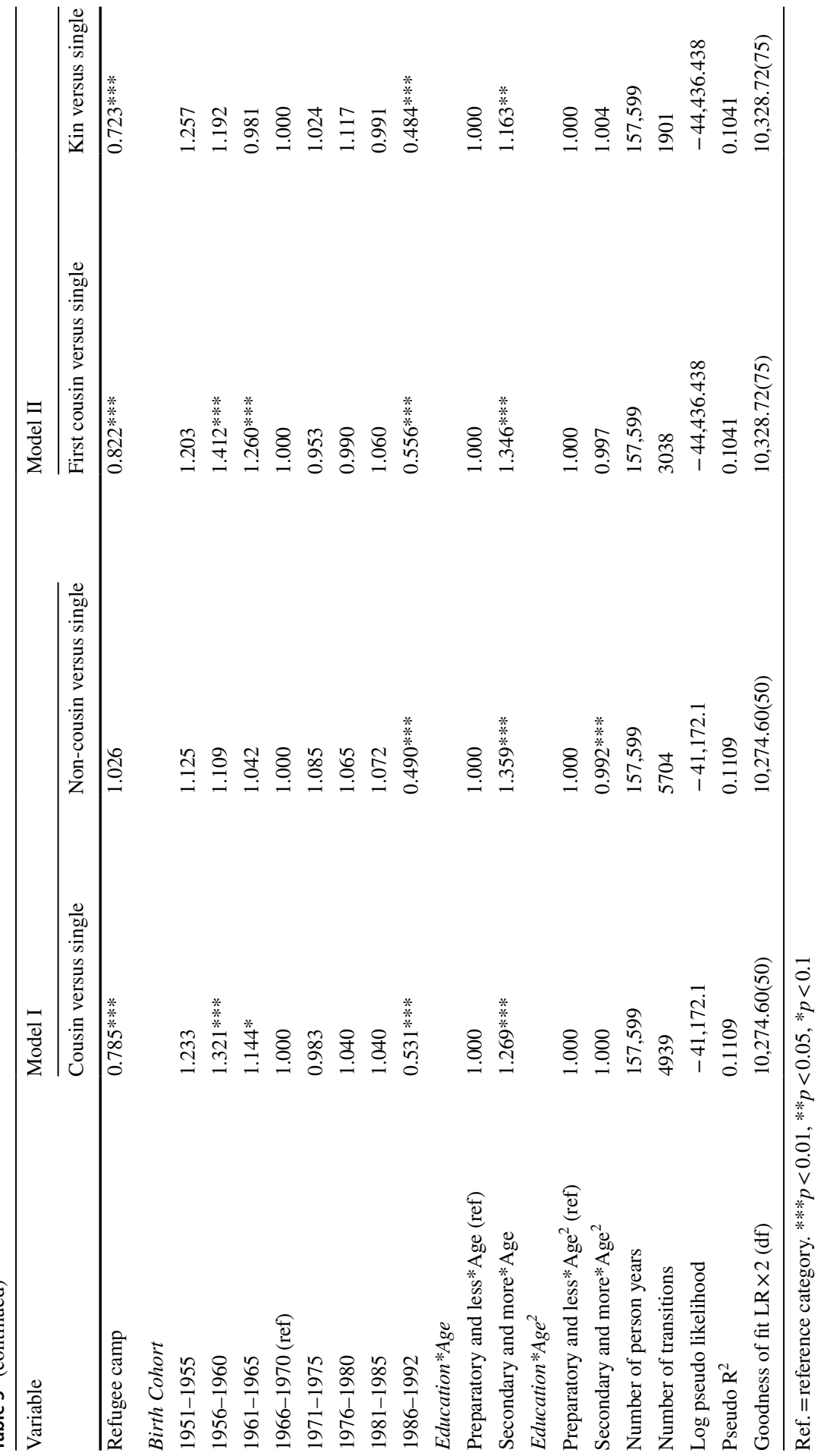




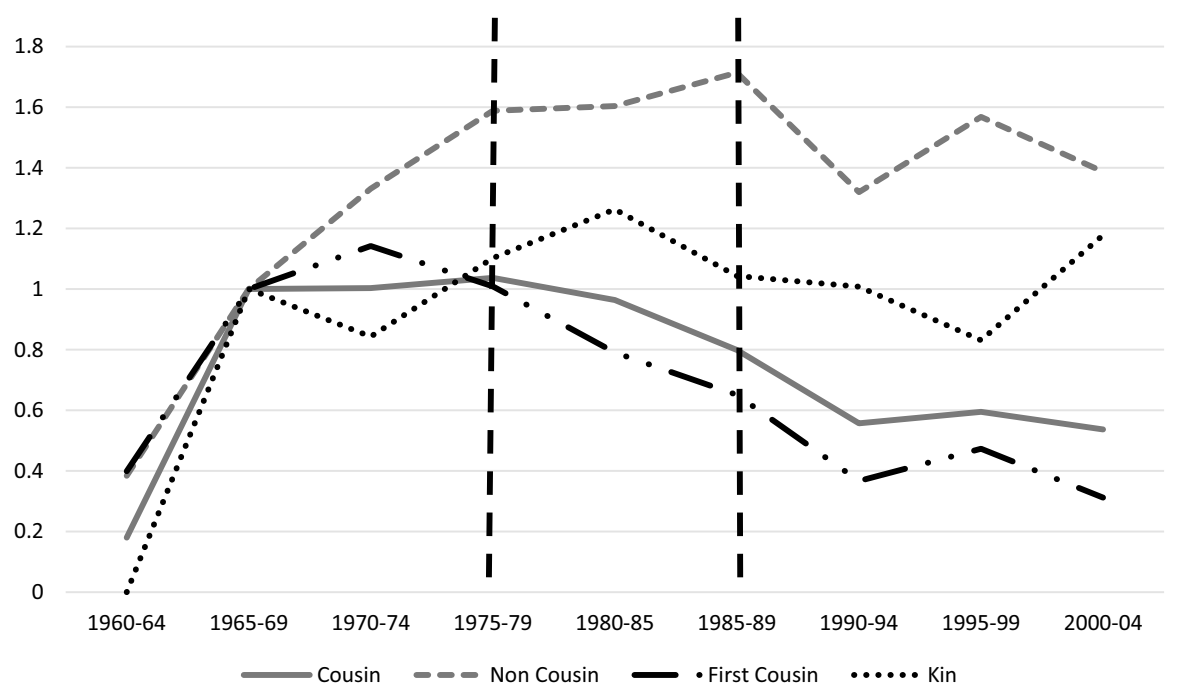

Fig. 5 Period Trends in Types of Marriages in terms of odds ratios, Lebanon 1960-2004. Note Figure reports results from Table 4 Cousin and Non Cousin (Model I), First Cousin and Kin (Model II); dashed vertical lines refer to the Period of Civil War

Results on the region of residence variables reveal that marriage propensity is higher for women in all regions in Palestine relative to residents in the Northern West Bank (Table 3) and only for women residing in the North in Lebanon (Table 2). However, to see whether the impact of war and conflict varies significantly with region of residence as is reported in other settings (Jayaraman et al., 2009; Valente, 2011), I add interactions between period and region to Model III in Tables 2 (Lebanon) and 3 (Palestine). Although the likelihood ratio tests show that there are significant interaction effects in both countries $(p$ value $=0.008)$, a comparison of the period effects by region did not reveal significant variations except for Gaza (see Supplemental Fig. A1) and Bekaa-though results were largely insignificant-(see Supplemental Fig. A2). Looking within locality in Palestine, results suggest that marriage propensity is lower for women living in rural areas and refugee camps compared to women living in urban areas.

To determine the impact of war and conflict on marriage type, Tables 4 and 5 present results from discrete-time multinomial logit models for type of marriage distinguishing cousin from non-cousin marriage (Model I) in Lebanon and Palestine respectively. The Models include time-varying period indicators with selected covariates to assess whether periods of conflict significantly affect cousin and noncousin marriage propensity. There is no evidence of a war effect on cousin marriage but a significant effect on non-cousin marriage in Lebanon (see Model I in Table 4) as evident by the significant civil war period indicators (1975-1989). These results are clearly visible through the declining solid line (cousin marriage) and increasing dashed line (non-cousin marriage) over the civil war period in Fig. 5. In Palestine however, there is clear evidence of a war effect on both cousin and non-cousin marriage as evident by the very significant effect of the period indicators representing 


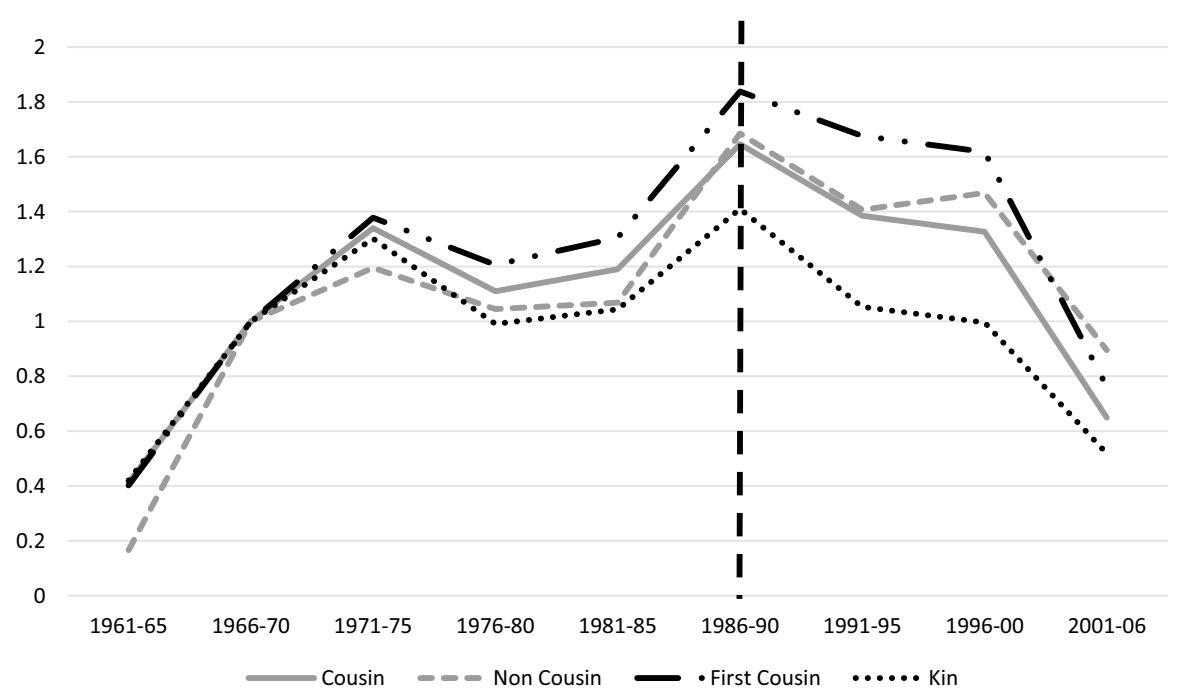

Fig. 6 Period Trends in Types of Marriages in terms of odds ratios, Palestine 1961-2006. Note Figure reports results from Table 5 Cousin and Non Cousin (Model I), First Cousin and Kin (Model II); dashed vertical line refers to the Period of First Intifada

the first intifada (1986-1990). These results are again clearly visible by the increasing solid (cousin marriage) and dashed (non-cousin marriage) lines during the first intifada period in Fig. 6. There is no evidence of an impact on marriage type for the war-cohorts in both countries. Overall, this suggests that war and conflict has resulted in a uniform conflict-induced increase in marriage behaviour in both countries through an increase in a specific type of marriage (non-cousin) in Lebanon and an indistinguishable increase in marriage behaviour overall (regardless of marriage type) in Palestine.

I again test whether the impact of war and conflict on marriage type varies significantly with level of education in both settings (likelihood ratio tests show that the interactions are significant in both countries, $p$ value $=0.000$ ). To do so, I present results from an interaction between time varying period indicators and education (Figs. 3 and 4). The results for cousin marriage (Fig. 3: Panel B) suggest that while cousin marriage propensity remained largely stable for highly educated women throughout the civil war period, it decreased for their less educated counterparts, thereby reducing the usual marriage propensity gap for women in both education groups. Qualitative results provide further support of how higher educated women continued the practice of cousin marriage. This is because the war made continued educational pursuit irrelevant but also because marriage presented an opportunity to strengthen existing familial ties.

"I continued my secondary education then the civil war started, my cousin and his family were living in Beirut and he was in his third year in French literature, I was living in the village and couldn't pursue my university degree because of the war and insecurities in leaving and moving, my family and my 
uncle's family had a good relationship, they came and officially proposed as there was no longer a reason to delay [in reference to the civil war]." Woman 55 years with secondary education from Lebanon.

A different pattern is observed for Palestinian women, whereby the cousin marriage propensity of both educated groups of women increased similarly during the first intifada period, thereby maintaining the usual gap in cousin marriage propensity among women in both education groups (Fig. 4: Panel B). Qualitative evidence provides further support of this. In fact, the following quote reveals how protection through cousin marriage is sought after in times of conflict for this secondary educated woman whose continued educational pursuit is no longer deemed relevant in light of perceived threats to her safety.

"I was in the 1st year of university in the West Bank and because of the political situation [referring to Intifada] I had to go back to Gaza, my cousin proposed, I wanted to continue my education but my family couldn't envision me going back to the West Bank to continue." Woman 42 years completed her 1st year of university from Palestine.

This provides evidence of my second hypothesis for Palestine. While the qualitative evidence for Lebanon helps show how cousin marriage could be used as an opportunity to strengthen existing familial ties for higher educated women in lack of further education opportunities, statistical results at the aggregate level (as noted above) do not support this.

The results for non-cousin marriage (Fig. 3: Panel C) are fairly similar to marriage overall in Lebanon (Panel A). That is, the propensity for non-cousin marriage increases for both education groups at the civil war onset but remains relatively stable throughout the war period albeit with a narrower gap between education groups in comparison to marriage more generally (Panel A). That said, the narrow gap between education groups is uniform across all periods (not only during the civil war)-what is different is the higher propensity in non-cousin marriage for women in both education groups during the civil war period (with a slightly higher propensity for the low educated throughout all periods). The same is observed in Palestine, non-cousin marriage propensity patterns (Fig. 4: Panel C) are similar to those of marriage overall (Panel A). In Palestine however, the gap between education groups completely closes, with women from both education groups having the same increased propensity in non-cousin marriage during the first intifada (with a steeper increase for the higher educated women). This provides support for my third hypothesis for both Lebanon and Palestine which stipulates that transition to non-cousin marriage is more likely during periods of war and conflict.

The results on region of residence variables from both countries reveal similar patterns between cousin and overall marriage propensities (Tables 4 and 5). The same pattern is also observed for non-cousin marriage in Palestine (Table 5), whereas non-cousin marriage is only more likely for women in the North of Lebanon (Table 4). I again tested for any significant variations in the impact of war with region of residence. While the likelihood ratio tests show that there are significant 
interaction effects in both countries ( $p$ values $=0.007$ in both countries), results were similar to marriage overall, where a comparison of the period effects by region did not reveal significant variations except for Gaza (see Supplemental Fig. A1) and Bekaa-though results here were largely insignificant-(see Supplemental Fig. A2).

Finally, qualitative results reveal that unlike women in urban and rural areas where families live within close proximities, women in the refugee camps were internally displaced as a result of the 1948 and 1967 wars and hence their families were separated from one another both in refugee camps within the West Bank but also in refugee camps in neighbouring countries and particularly Jordan given its proximity to Palestine. While the oldest cohorts included in the analysis were born in the early 1950s, the ramifications of the 1948 and 1967 wars have had major repercussions for their families (parents) and the population at large. This is manifested through forced displacement and migration to neighbouring countries in the region that resulted in the consequent breakage of kinship and family networks, including the separation of families across different borders. In fact, fieldwork reveals a degree of cross-border marriages where women are brought in from Jordan to marry their cousins in the refugee camps of the West Bank. More recently however, this is costly and increasingly difficult especially for women that have no West Bank identity cards, making it only possible for families that can afford it. This explains why transition to cousin marriage is lower for women residing in refugee camps compared to those in urban areas (Table 5).

\section{Robustness check: dividing consanguinity into first cousin and kin}

I conduct a robustness check by separating consanguinity into first-cousin and kin to see if conflict-induced impact on marriage type is maintained in both countries. Results are largely unchanged, but the separation reveals that while results from consanguinity showed no impact of war on cousin marriage formation in Lebanon, separating consanguinity into first cousin and kin reveals that kin marriages are significantly more likely for women from the war cohort (Model II in Table 4). ${ }^{14}$ Figure 5 shows such an effect through the noted increase in kin marriage (dotted line) during the civil war period. ${ }^{15}$ It also clearly shows how first cousin marriage (two dotted dashed line) declined during the civil war period. For Palestine, results remain largely unchanged even after separating consanguinity into first cousin and kin. That is, the conflict-induced increase in consanguineous marriages were still observed but we now know that the conflict-induced increase in cousin marriage is largely driven by an increase in first cousin marriage formation during the first intifada period (Model II in Table 5). Figure 6 shows this through the steep increase in first cousin marriage formation (two dotted dashed line) during the first Intifada period.

\footnotetext{
14 I borrow the term 'war cohort' from Shemyakina (2013) and use it to mean the cohort of women that were of prime marriageable ages during the civil war onset in Lebanon and the first Intifada in Palestine. 15 Although this is not significant according to Model II in table 4 for Lebanon.
} 


\section{Discussion and conclusion}

A growing body of research is looking at demographic behaviour in times of war. While the number of studies on marriage formation as a demographic outcome in such periods are slowly emerging, studies on consanguinity in times of war are rarely explored. This paper contributes to this nascent literature, extends it to consanguinity and leverages a mixed methods approach. Further, it offers a more nuanced perspective to the study of demographic behaviour in times of war by borrowing from the literature on social ties/capital to examine potential social war-induced mechanisms. The results in this paper point to the significant effect of the civil war (1975-1990) in Lebanon and the first Intifada (1987-1993) in Palestine on marriage formation. Indeed, women and their families resort to marriage as a protective strategy in times of war and when the continued educational pursuit is no longer deemed relevant because of both perceived and actual threats to women's safety. Hence, the paper contributes to the literature on 'demography of conflicts' (Randall, 2005). ${ }^{16}$ Most clearly, results point to consanguinity being used as a strategy to strengthen solidarity and familial bonds in times of war, especially for Palestinian women. Indeed, a uniform conflict-induced effect is evident for Palestinian women especially for first cousin marriage formation. This is not evident for Lebanese women. Remarkably, the desire to establish new alliances to non-relatives in times of war is equally present for both Lebanese and Palestinian women. Overall, what is evident, is that war and conflict increase the attractiveness of marriage as a protective mechanism for women and their families regardless of the setting in which it takes place. The strategies devised however, differ across both settings, with women in Lebanon mainly strategizing out-group marriages in an attempt to diversify resources through the establishment of new alliances, whereas the strategies devised by Palestinian women and their families show more heterogeneity. That is, maintenance of existing familial bonds through in-group marriages and diversification of resources through outgroup marriages that facilitate new alliances.

Results also show a significant impact of war and conflict on marriage by level of education. This operates by narrowing the gap in marriage propensity (that usually exists among low and high educated women in favour for the low educated during conflict free periods) by rendering marriage especially more likely for the highly educated in times of war in both countries. This operates the same way regardless of marriage type with the exception of cousin marriage in both countries. For Lebanese women, cousin marriage propensity remained fairly stable for highly educated women throughout the civil war period, while it decreased for their lower educated counterparts. For Palestinian women however, the gap in marriage propensity among both groups of women remained fairly stable as cousin marriage propensity increased for both the high and low educated groups of women during the first intifada. There is no evidence of a significant regional variation in the impact of conflict

\footnotetext{
16 Randall (2005) posits that the "importance of unique historical, political and cultural experiences of a population in responding to conflict precludes the development of a 'demography of conflict'" (p.291) hence the term 'demography of conflicts'.
} 
and war on marriage or marriage type in either setting except for Gaza where the impact is positive for both.

The differences in the conflict-induced marriage propensities for different types of marriages by study setting might be indicative of other context contingent conflict-induced mechanisms. These could operate through distorted sex-ratios against women in Lebanon and through the breakage of kin networks through forced migration/displacement in Palestine. Indeed, Saxena (2004) reports distortions in the marriage market against females (because of imbalances in sex-ratios through higher male mortality and higher male labor migration) as a result of the civil war in Lebanon. This might have further reduced the number of eligible male cousins for women to choose from in Lebanon resulting in a conflict-induced increase in noncousin marriage. The breakage of kin and familial networks as a result of forced displacement and migration following the 1948 and 1967 wars in Palestine might be driving the indistinguishable war-induced increase in marriage propensity (regardless of marriage type) in Palestine. Indeed, as noted by Hilal (2006) and Gordon (2008) under the Jordanian administrative rule of the West Bank between 1948 and 1967, hamula (kin/clan) identification was prompted as a means for suppressing Palestinian nationalism. This practice- which might strengthen consanguinity- was further promoted by Israel when it occupied the West Bank and Gaza in 1967 (Harker, 2010). But the separation of families across different borders with subsequently different citizenships by the nature of state boundaries drawn (Joseph \& Rieker, 2008) might have prevented some women and their families from exercising this preference. This might explain the conflict-induced increase in both cousin and noncousin marriage in Palestine.

Taken together, results point to the sensitivity of marital behaviour in times of war in both settings, a result that can be easily extrapolated to other war settings, thereby extending the evidence base on marriage formation as a demographic outcome in times of conflict and war (Clifford et al., 2010; Jayaraman et al., 2009; Randall, 2005; Shemyakina, 2013; Teerawichitchainan, 2012; Valente, 2011). The specific marital behaviour however, including the strategies that women and their families devise in times of war may have more resonance within the specific geographic region in which these two countries are situated. Indeed, the lack of a welfare state- a situation that characterises most of the countries in the region, places higher prominence on the role of families especially in providing essential safety nets. This becomes even more salient in times of conflict as the family takes on the protective role in times of insecurities. Marital behaviour is one dimension that families have relative control over, and they do so devising strategies that diversify resources and/or consolidate alliances, thereby strengthening the ties that bind but also recognising the strength of the ties that bridge in diversifying resources by building new alliances through marriage.

This paper does come with some caveats. First, while results point to the effect of war and conflict on marital behaviour, the datasets I use are fairly dated. Nevertheless, they are the only datasets that allow for such a comparative analysis from two countries with conflicts that are different in nature, roughly comparable in time periods and with datasets from both countries being two years apart. This makes such 
an analysis unique and largely unattainable with different datasets. ${ }^{17}$ Second, while results reveal a war-induced difference in marriage propensity by education group, the data on education is only collected at the time of the survey and hence prevent me from carefully distinguishing between causation and reverse causation in the relationship between war, education and marriage formation. I therefore could not differentiate whether the inability to pursue education is a cause or consequence of conflict-induced marriage formation. Third, I was only able to speculate the reasons behind the differences in the conflict-induced marriage propensities for different types of marriages I found by setting. This is because data limitations prevented me from empirically examining the distortions in sex-ratios against women in Lebanon and the breakage of kin-networks from war displacement in Palestine that were reported in the literature.

That said, while the results refer to marital behaviour in response to a civil war and a first Intifada that have long passed, the continued conflict and Israeli Occupation in Palestine and the ongoing conflicts in the region, that have only increased in the recent period makes the results of this study especially timely. Indeed, with ongoing conflicts in Iraq, Yemen and especially neighbouring Syria, the results are indicative of similar demographic responses in times of war. In fact, studies have pointed to the effect of war on marital and fertility behaviour in Iraq where warinduced an increase in marriage formation particularly early marriage for women with low levels of education (Cetorelli, 2014).

Further, not only do these results relate to countries in the region, but they do offer insights to other world regions that have received a large share of this region's population in the form of forced displacement. Notwithstanding the complex family dynamics associated with forced displacement (Abbasi-Shavazi et al., 2018), marital behaviour patterns revealed in this paper are indicative of other populations from the region particularly from Iraq and Syria that have been largely displaced in neighbouring countries within the region but also elsewhere, especially in Europe. Whether the large scale of forced displacement from the region and its impacts on marriage and family formation is likely to result in persistent or transient changes to the family more broadly remains to be seen by future research. This will hence determine the pace of family change in the region and for its displaced population elsewhere.

Supplementary Information The online version contains supplementary material available at https://doi. org/10.1007/s12546-022-09281-9.

Acknowledgements Thanks to Dennis Hogan, Michael White, and Marwan Khawaja for helpful comments and suggestions on earlier drafts. Thanks also to interview participants in Lebanon and Palestine for their time to recount their experiences, for Haneen Razg and Kawthar Abu Khalil for research assistance, and for Huda Zurayk and Carla Makhlouf Obermeyer from the Faculty of Health Sciences at the American University of Beirut and Rita Giacaman from the Institute of Community and Public Health at Birzeit University for providing office space during fieldwork in both countries. Finally, thanks to anonymous reviewers for helpful suggestions. The financial support at different stages of research was provided

\footnotetext{
17 While there are more recent survey datasets from Palestine, there are no recent datasets from Lebanon that allow for such an analysis.
} 
by the Sociology Department at Brown University, the Population Studies and Training Centre at Brown University, and the Australian Research Council (ARC) Centre of Excellence for Children and Families over the Life Course (project number CE140100027) at the University of Queensland. The findings and views reported in this paper are those of the author alone. Any shortcomings are the author's own responsibility.

Funding Open Access funding enabled and organized by CAUL and its Member Institutions.

\section{Declarations}

Conflict of interest The author declares that there is no conflict of interest.

Open Access This article is licensed under a Creative Commons Attribution 4.0 International License, which permits use, sharing, adaptation, distribution and reproduction in any medium or format, as long as you give appropriate credit to the original author(s) and the source, provide a link to the Creative Commons licence, and indicate if changes were made. The images or other third party material in this article are included in the article's Creative Commons licence, unless indicated otherwise in a credit line to the material. If material is not included in the article's Creative Commons licence and your intended use is not permitted by statutory regulation or exceeds the permitted use, you will need to obtain permission directly from the copyright holder. To view a copy of this licence, visit http://creativecommons.org/licen ses/by/4.0/.

\section{References}

Abbasi-Shavazi, M., McDonald, P., \& Hosseini-Chavoshi, M. (2008). Modernization or cultural maintenance: The practice of consanguineous marriage in Iran. Journal of Biosocial Science, 40, 911-933.

Abbasi-Shavazi, M. Mahmoudian, H., \& Sadeghi, R. (2018). Family dynamics in the context of forced migration. In Hugo, G., Abbasi-Shavazi, M. \& Kraly, E, (Ed.) Demography of refugee and forced migration, pp. 155-174, Chapter 8, Springer.

Agadjanian, V., \& Makarova, E. (2003). From soviet modernization to post-soviet transformation: Understanding marriage and fertility dynamics in Uzbekistan. Development and Change, 34(3), 447-473.

Al-Gazali, L., \& Hamamy, H. (2014). Consanguinity and dysmorphology in Arabs. Human Hereditary, 77, 93-107.

Allison, P. (1984). Event history analysis: Regression for longitudinal event data. Sage.

Assaf, S., \& Khawaja, M. (2009). Consanguinity trends and correlates in the Palestinian territories. Journal of Biosocial Science, 41, 107-124.

Assaf, S., \& Chaban, S. (2013). Domestic violence against single, never-married women in the occupied palestinian territory. Violence against Women, 19(3), 422-441.

Barakat, B., \& Basten, S. (2014). Modelling the constraints on consanguineous marriage when fertility declines. Demographic Research, 30, 277-312.

Barakat, H. (1985). The Arab family and the challenge of social transformation. In F. E. Warnock (Ed.), Women and the family in the Middle East: New voices of change (pp. 27-48). University of Texas Press.

Barakat, H. (1993). The Arab world: Society, culture, and state. University of California Press.

Bittles, A. (2015). The prevalence and outcomes of consanguineous marriage in contemporary societies. In A. Shaw \& A. Raz (Eds.), Cousin marriages: Between tradition, genetic risk and cultural change (pp. 33-45). Berghahn Books.

Bittles, A., \& Hamamy, H. (2010). Endogamy and consanguineous marriage in Arab populations. In A. Teebi (Ed.), Genetic disorders among Arab populations (pp. 85-108). Springer-Verlag.

Bourdieu, P. (1980). Le capital social: Notes provisoires. Actes De La Recherche En Sciences Sociales, $3,2-3$.

Bourdieu, P. (1983/1986). The forms of social capital. In J. G. Richardson (Ed.), Handbook of theory and research for the sociology of education. pp. 241-258. Greenwood Press. 
Brück, T., Justino, P., Verwimp, P., \& Avdeenko, A. (2010). Identifying conflict and violence in microlevel surveys. IZA Discussion Paper Series, 5067, 1-62.

Cetorelli, V. (2014). The effect on Fertility of the 2003-2011 War in Iraq. Population and Development Review, 40(4), 581-604.

Chamarbagwala, R., \& Moran, H. (2011). The human capital consequences of civil war: evidence from Guatemala. Journal of Development Economics, 94, 41-61.

Chamie, J. (1977). Religious differentials in fertility: Lebanon, 1971. Population Studies, 31, 365-382.

Clifford, D., Falkingham, J., \& Hinde, A. (2010). Through civil war, food crisis and drought: Trends in fertility and nuptiality in post-Soviet Tajikistan. European Journal of Population, 26, 325-350.

Coleman, J. S. (1988). Social capital in the creation of human capital. American Journal of Sociology, 94, S95-S121.

Courbage, Y., \& Todd, E. (2014). A convergence of civilizations: The transformation of Muslim societies around the world. Columbia University Press.

Erickson, B. H. (1996). A structural approach to network and cultural resources. University of Toronto.

De Koning, M., Storms, O., \& Bartels, E. (2014). Legal "ban” on transnational cousin-marriages: Citizen debate in the Netherlands. Transnational Social Review, 4, 226-241.

Falkingham, J. (2000). Women and gender relations in Tajikistan. Country Briefing Paper. Asian Development Bank Programs Dept. East and Office of Environment and Social Development: Manila pp. 1-139.

Faour, M. (2007). Religion, demography and politics in Lebanon. Middle Eastern Studies, 43, 909-921.

Giacaman, R., Khatib, R., Shabaneh, L., Ramlawi, A., Sabri, B., Sabatinelli, G., Khawaja, M. \& Laurance, T. (2009). Health in the Occupied Palestinian Territory 1: Health Status and Health Services in the Occupied Palestinian Territory, Lancet-March, pp. 15-27.

Goode, W. (1963). World revolution and family Patterns. The Free Press.

Gordon, N. (2008). Israel's occupation. University of California Press.

Haj, S. (1992). Palestinian women and patriarchal relations. Signs, 17, 761-778.

Harker, C. (2010). On (not) forgetting families: Family spaces and spacings in Birzeit, Palestine. Environment and Planning A, 42, 2624-2639.

Harkness, G., \& Khaled, R. (2014). Modern traditionalism: Consanguineous marriage in Qatar. Journal of Marriage and Family, 76, 587-603.

Hilal, J. (2006). Emigration, conservatism and class formation in West Bank and Gaza communities. In L. Taraki (Ed.), Living Palestine: Family survival, resistance, and mobility under Occupation (pp. 185-230). Syracuse University Press.

Hoben, A., Buunk, A., \& Fisher, M. (2015). Factors influencing the allowance of cousin marriages in the standard cross cultural sample. Evolutionary Behavioural Sciences, 10(2), 98-108.

Holy, L. (1989). Kinship, honour and solidarity: Cousin-marriage in the Middle East. Manchester University Press.

Hudson, M. (1985). The precarious republic: Political modernization in Lebanon. Westview Press.

Islam, A., Ouch, C., Smyth, R., \& Wang, L. C. (2016). The long-term effects of civil conflicts on education, earnings, and fertility: Evidence from Cambodia. Journal of Comparative Economics, 44, $800-820$.

Jayaraman, A., Gebreselassie, T., \& Chandrasekhar, S. (2009). Effect of conflict on age at marriage and age at first birth in Rwanda. Population Research Policy Review, 28(5), 551-567.

Johnson, P. (2006). Living together in a nation in fragments: Dynamics of kin, place and nation. In L. Taraki (Ed.), Living Palestine: Family survival, resistance, and mobility under Occupation (pp. 51-102). Syracuse University Press.

Johnson, P., Abu Nahleh, L., \& Moors, A. (2009). Weddings and war: Marriage arrangements and celebrations in two Palestinian Intifadas. Journal of Middle East Women's Studies, 5, 11-35.

Johnson, P. (2010). Unmarried in Palestine: Embodiment and (dis)empowerment in the lives of single Palestinian women. IDS Bulletin, 41, 106-115.

Joseph, S. (2000). Civic myths, citizenship, and gender in Lebanon. In S. Joseph (Ed.), Gender and citizenship in the Middle East (pp. 107-136). Syracuse University Press.

Joseph, S. (2004). Conceiving family relationships in post-war Lebanon. Journal of Comparative Family Studies, pp. 271-293.

Joseph, S., \& Rieker, M. (2008). Submitted introduction: Rethinking arab families projects. In A. F. W. Group (Ed.), Framings: Rethinking arab families projects (pp. 1-30). Syracuse University Press.

Jurdi, R., \& Saxena, P. (2003). The prevalence and correlates of consanguineous marriages in Yemen: Similarities and contrasts with other Arab countries. Journal of Biosocial Science, 35, 1-13. 
Justino, P. (2016). Supply and demand restrictions to education in conflict-affected countries: New research and future agendas. International Journal of Educational Development, 47, $76-85$.

Kalmijn, M. (2013). The educational gradient in marriage: A comparison of 25 European Countries. Demography, 50, 1499-1520.

Khawaja, M. (2000). The recent rise in Palestinian fertility: Permanent or transient? Population Studies, 45, 331-346.

Khawaja, M., \& Randall, S. (2006). Intifada, Palestinian fertility and women's education. Genus, LXII, pp. 21-51.

Laub, J., \& Sampson, R. (1998). Integrating quantitative and qualitative data. Methods of life course research: qualitative and quantitative approaches (pp. 213-230). Sage.

Lin, N. (2005). A network theory of social capital. In D. Castiglione, J. van Deth, \& G. Wollen (Eds.), Handbook on social capital (pp. 1-25). Oxford University Press.

McDonald, P. (1985). Social organization and nuptiality in developing societies. In J. Cleland \& J. Hobcraft (Eds.), Reproductive change in developing countries: insights from the world fertility survey (pp. 87-114). Oxford University Press.

Mobarak, A., Kuhn, R., \& Peters, C. (2013). Consanguinity and other marriage market effects of a wealth shock in Bangladesh. Demography, 50, 1845-1871.

Moors, A. (1995). Women, property, and islam: Palestinian experiences, 1920-1990. Cambridge University Press.

Murphy, M. (2011). Long-term effects of the demographic transition on family and kinship networks in Britain. Population and Development Review, 37, 55-80.

Olmsted, J. (1999). Economic history, Middle East and North Africa. In J. Peterson \& M. Lewis (Eds.), The elgar companion to feminist economics (pp. 219-226). Edward Elgar.

Olmsted, J. (2005). Gender, aging, and the evolving arab patriarchal contract. Feminist Economics, 11(2), 53-78.

PAPFAM. (2006). Lebanon Family Health Survey, 2004: Principle Report. Lebanon.

PCBS. (2007). Palestinian Family Health Survey, 2006: Preliminary Report. Ramallah, Palestine.

PCBS. (2013). Palestinian Family Survey, 2010: Final Report. Ramallah, Palestine.

Putnam, R. D. (1995). Bowling alone: American's declining social capital. Journal of Democracy, 6(1), 65-78.

Randall, S. (2005). The demographic consequences of conflict, exile and repatriation: A case study of Malian Tuareg. European Journal of Population, 21, 291-320.

Rashad, H., \& Osman, M. (2003). Nuptiality in arab countries: Changes and implications. In N. Hopkins (Ed.), The New Arab Family (pp. 20-44). The American University in Cairo Press.

Rashad, H., Osman, M., \& Roudi-Fahimi, F. (2005). Marriage in the Arab World (pp. 1-8). Policy Brief. Population Reference Bureau.

Romeo, G., \& Bittles, A. (2014). Consanguinity in the contemporary world. Human Heredity, 77, 6-9.

Sandridge, A., Takeddine, J., Al-Kaabi, E., \& Frances, Y. (2010). Consanguinity in Qatar: Knowledge, attitude and practice in a population born between 1946 and 1991. Journal of Biosocial Science, 42, 59-82.

Saxena, P., Kulczycki, A., \& Jurdi, R. (2004). Nuptiality transition and marriage squeeze in Lebanon: Consequences of sixteen years of civil war. Journal of Comparative Family Studies, 35(2), 241-258.

Sayigh, R. (1981). Role and function of Arab women: A reappraisal. Arab Studies Quarterly, 3(3), 258-274.

Sayigh, R. (2005). The kin contract and citizenship in the Middle East. In M. Friedman (Ed.), Women and Citizenship (pp. 149-169). Oxford University Press.

Sayigh, R. (2008). Familism and critical arab family studies. In K. Yount \& H. Rashad (Eds.), Family ties and ideational change in the Middle East (pp. 25-39). Routledge.

Schellekens, J., Kenan, G., \& Hleihel, A. (2017). The decline in consanguineous marriage among Muslims in Israel: The role of education. Demographic Research, 27(61), 1933-1948.

Shaw, A., \& Raz, A. (2015). Introduction. In A. Shaw \& A. Raz (Eds.), Cousin marriages: Between tradition, genetic risk and cultural change (pp. 1-32). Berghahn Books.

Shemyakina, O. (2011). The effect of armed conflict on accumulation of schooling: Results from Tajikistan. Journal of Development Economics, 95, 186-200.

Shemyakina, O. (2013). Patterns in female age at first marriage and tajik armed conflict. European Journal of Population, 29, 303-343.

Shehadeh, L. R. (1998). The legal status of married women in Lebanon. International Journal of Middle East Studies, 30(04), 501-519. 
Shultz, E., \& Lavenda, R. (2000). Cultural anthropology: A perspective on the human condition. McGraw-Hill.

Small, M. (2011). How to conduct a mixed methods study: Recent trends in a rapidly growing literature. Annual Review of Sociology, 37, 57-86.

Swee, E. L. (2015). On war intensity and schooling attainment: The case of Bosnia and Herzegovina. European Journal of Political Economy, 40, 158-172.

Tabutin, D., \& Shoumaker, M. (2005). The demography of the Arab World and the Middle East from the 1950 s to the 2000s. Population (English Edition), 60, 505-615.

Taraki, L., \& Giacaman, R. (2006). Modernity aborted and reborn: Ways of being urban in Palestine. In L. Taraki (Ed.), Living Palestine: Family survival, resistance, and mobility under Occupation (pp. 1-50). Syracuse University Press.

Teerawichitchainan, B. (2012). War, Military Service, and Union Formation in Northern Vietnam. Paper presented at the Population Association of American Annual Meeting, 3-5 May 2012, San Francisco. Available at: http://ink.library.smu.edu.sg/soss_research/1334. Accessed 24 May 2017.

Tfaily, R. (2005). First cousin marriages and marital relationships: evidence from Egypt, Jordan, Turkey and Yemen. XXV International Population Conference, International Union for the Scientific Study of Population (IUSSP), Torres, France. Available at: http://iussp2005.princeton.edu/papers/52026. Accessed 20 May 2017.

Thaler, K. (2015). Mixed methods research in the study of political and social violence and conflict. Journal of Mixed Methods Research, pp. 1-18.

United Nations, Department of Economic and Social Affairs, Population Division (2013). World Marriage Data 2012 (POP/DB/Marr/Rev2012).

Valente, C. (2011). What did the Maoists ever do to us? Education and marriage of women exposed to civil conflict in Nepal. World Bank Policy Research Working Paper. WPS5741, pp. 1-49.

Weinreb, A. (2008). Characteristics of women in consanguineous marriages in Egypt, 1988-2000. European Journal of Population, 24, 185-210.

Welchman, L. (2000). Beyond the Code: Muslim Family Law and the Shari'a Judiciary in the Palestinian West Bank. BRILL.

World Population Data Sheet. (2015). Population Reference Bureau.

Wu, L. (2003). Event history models for life course analysis. In J. Mortimer (Ed.), Handbook of the life course (pp. 477-502). Kluwer Academic Publishers.

Publisher's Note Springer Nature remains neutral with regard to jurisdictional claims in published maps and institutional affiliations.

\section{Authors and Affiliations}

\section{Yara Jarallah $^{1,2,3,4}$ (I)}

1 Te Ngira: Institute for Population Research (formerly NIDEA), University of Waikato, Hamilton, New Zealand

2 Melbourne School of Population and Global Health, The University of Melbourne, Melbourne, Australia

3 ARC Centre of Excellence for Children and Families Over the Life Course, Institute for Social Science Research, The University of Queensland, Brisbane, Australia

4 Population Studies and Training Centre, Brown University, Providence, USA 